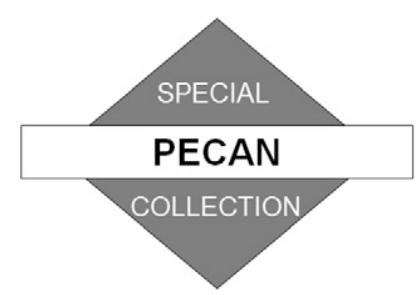

\title{
Understanding the Impact of Radar and In Situ Observations on the Prediction of a Nocturnal Convection Initiation Event on 25 June 2013 Using an Ensemble-Based Multiscale Data Assimilation System
}

\author{
Samuel K. Degelia And Xuguang Wang \\ School of Meteorology, University of Oklahoma, Norman, Oklahoma
}

DAVID J. STENSRUD

Department of Meteorology and Atmospheric Science, The Pennsylvania State University, University Park, Pennsylvania

AARON JOHNSON

School of Meteorology, University of Oklahoma, Norman, Oklahoma

(Manuscript received 9 May 2017, in final form 17 April 2018)

\begin{abstract}
The initiation of new convection at night in the Great Plains contributes to a nocturnal maximum in precipitation and produces localized heavy rainfall and severe weather hazards in the region. Although previous work has evaluated numerical model forecasts and data assimilation (DA) impacts for convection initiation (CI), most previous studies focused only on convection that initiates during the afternoon and not explicitly on nocturnal thunderstorms. In this study, we investigate the impact of assimilating in situ and radar observations for a nocturnal CI event on 25 June 2013 using an ensemble-based DA and forecast system. Results in this study show that a successful CI forecast resulted only when assimilating conventional in situ observations on the inner, convection-allowing domain. Assimilating in situ observations strengthened preexisting convection in southwestern Kansas by enhancing buoyancy and locally strengthening low-level convergence. The enhanced convection produced a cold pool that, together with increased convergence along the northwestern low-level jet (LLJ) terminus near the region of CI, was an important mechanism for lifting parcels to their level of free convection. Gravity waves were also produced atop the cold pool that provided further elevated ascent. Assimilating radar observations further improved the forecast by suppressing spurious convection and reducing the number of ensemble members that produced $\mathrm{CI}$ along a spurious outflow boundary. The fact that the successful CI forecasts resulted only when the in situ observations were assimilated suggests that accurately capturing the preconvective environment and specific mesoscale features is especially important for nocturnal CI forecasts.
\end{abstract}

\section{Introduction}

Warm season precipitation forecasting remains a difficult problem, as forecast accuracy is consistently higher in the cool season than in the summer (Fritsch and Carbone 2004). Forecasting warm season precipitation at night provides additional challenges, as forecasts of nocturnal convective storms in the United States are less accurate than forecasts of daytime storms (Davis et al. 2003). Additionally, nocturnal convection produces

\footnotetext{
Corresponding author: Samuel K. Degelia, sdegelia@ou.edu
}

many flash flooding events (Maddox et al. 1979) that often result in more deaths in the United States per year than any other severe weather-related hazard (NOAA 2004). Considering the well-documented nocturnal maximum in precipitation in the Great Plains of the United States (Wallace 1975; Surcel et al. 2010), improving forecasts of nocturnal convection during the summer is crucial.

Previous studies have related the nocturnal precipitation maximum to the eastward movement of mesoscale convective systems (MCSs) that initiate over higher terrain to the west during the afternoon (Carbone et al. 2002; 
Carbone and Tuttle 2008; Parker and Ahijevych 2007; Keenan and Carbone 2008). However, new storms often initiate at night that contribute to the nocturnal precipitation maximum (Bodine and Rasmussen 2017; Reif and Bluestein 2017). Though the various physical mechanisms responsible for generating convection during the afternoon have been studied in detail (e.g., Wilson and Schreiber 1986; Moncrieff and Liu 1999; Weckwerth and Parsons 2006; Wilson and Roberts 2006; French and Parker 2008), the exact processes responsible for convection initiation (CI) at night are less clear. Determining the processes that lead to nocturnal CI provides a unique challenge, as the various mechanisms responsible often interact and occur at different scales (Carbone and Tuttle 2008). The hypothesized mechanisms for both sustaining MCSs at night and initiating new convection include potential vorticity (PV) anomalies in the lee of the Rocky Mountains (Carbone et al. 2002; Li and Smith 2010), convective feedbacks such as gravity waves and bores (Carbone et al. 2002; Marsham et al. 2011), and the Great Plains low-level jet (LLJ; Pitchford and London 1962; Trier and Parsons 1993; Higgins et al. 1997). The LLJ is a particularly important phenomenon that provides a source of buoyancy (Trier and Parsons 1993; Helfand and Schubert 1995; Higgins et al. 1997) and forcing (Pitchford and London 1962; Trier and Parsons 1993; Augustine and Caracena 1994) for nocturnal convection. The exact mechanisms can be highly case dependent, and it is also likely that the above mechanisms are interrelated.

Additionally, nocturnal CI tends to be elevated, wherein the parcels that reach their level of free convection (LFC) originate above the boundary layer (Glickman 2000). As the source air for convection that develops above the planetary boundary layer (PBL) is not always clear, forecasting elevated convection using a proximity sounding can lead to operational difficulties (Corfidi et al. 2008). Elevated convection nevertheless produces all types of severe weather hazards, including severe wind, hail, tornadoes, and flash flooding (Rochette and Moore 1996; Horgan et al. 2007).

Numerical weather prediction (NWP) models often struggle with accurately predicting $\mathrm{CI}$ even during the afternoon (e.g., Wilson and Roberts 2006; Xue and Martin 2006; Kain et al. 2013). Small variations in the storm-scale or mesoscale environments produce significantly different results regarding timing, location, and structure of new convective development (Fabry 2006; Martin and Xue 2006). Kain et al. (2013) found that convection-allowing models provide some skill in predicting both the timing and location of diurnal CI, even though many convective processes occur at a subgrid scale. Johnson and Wang (2017) and Johnson et al. (2017) were among the first to systematically study the design of a convection-allowing ensemble data assimilation (DA) and forecast system for nocturnal convection. They performed real-time numerical predictions for nocturnal convection during the Plains Elevated Convection at Night (PECAN) experiment and found that their ensemble forecasts initialized at 1200 UTC were nearly unbiased regarding the timing of nocturnal CI.

The assimilation of synoptic- and mesoscale observations can improve the analyses of convergent boundaries, as well as the thermodynamic and kinematic environments in which storms form. Childs et al. (2006) showed improved CI forecasts by assimilating surface observations that induced convergent boundaries through enhanced surface heat fluxes. More recently, Sobash and Stensrud (2015) found positive results by using an ensemble Kalman filter (EnKF) to assimilate mesonet and conventional surface observations. Forecast improvements were found to have resulted from a better analysis of moisture within the PBL. Additionally, the assimilation of radar observations (radar reflectivity factor and radial velocity) has shown large impacts toward improving forecasts of severe convection by both suppressing spurious convection (e.g., Tong and Xue 2005; Aksoy et al. 2009; Yussouf and Stensrud 2010) and directly placing convection in the model instead of having to spin up preexisting storms (e.g., Johnson et al. 2015; Jones et al. 2015; Yussouf et al. 2015; Wang and Wang 2017). Only a few published DA studies have specifically studied the impact of assimilating radar observations on CI forecasts. For example, Thompson (2014) found improvements in cold pool forecasts after using radar data to better confine preexisting storms. The improved cold pool forecast was shown to be an important mechanism for generating afternoon convection.

The abovementioned DA impact studies focused primarily on convection that initiated during the daytime instead of at night. However, as both the thermodynamic environments and dynamic forcing mechanisms responsible for producing convection are fundamentally different after sunset, the impacts of storm-scale DA cannot be assumed to be the same between day and night. This study presents a novel analysis of the impacts that assimilating in situ, as well as radar, observations have on forecasts of an elevated, nocturnal CI event. On 24 June 2013, a late afternoon MCS initiated off a dryline in southwestern Kansas before dissipating in the early evening hours of 25 June (Fig. 1). Operational forecasts for the area predicted that storm chances would diminish rapidly by sunset due to the loss of daytime heating. However, isolated convection initiated shortly after sunset and later merged into an 
MCS that produced both severe wind and large hail. This study applies an advanced, multiscale DA system (Johnson et al. 2015) to the nocturnal CI case on 25 June 2013 to evaluate the impact of assimilating radar and in situ observations on the prediction of nocturnal CI. After presenting an overview of the analysis and forecast differences between experiments with each observation type assimilated, the mechanisms responsible for producing $\mathrm{CI}$ are diagnosed to better relate the observation impacts specifically to the CI process.

Section 2 contains an overview of the 25 June 2013 event, whereas the model and DA system configuration and experimental design are described in section 3 . Section 4 focuses on the observation impacts on the analyses and CI forecasts. Observation impacts on the hypothesized CI mechanisms are presented in section 5 . Finally, a summary and discussion of future work are contained in section 6 .

\section{Observational overview of 25 June 2013 CI event}

This study focuses on a cluster of isolated, nocturnal convection that initiated in northwestern Kansas (Fig. 1e) in an environment with a stable boundary layer. Prior to CI, an upper-level short wave moved from the northern Pacific coast to the Rocky Mountains. As the perturbation moved over the Rockies, deep southwesterly flow increased, and a lee trough developed near the surface. A dryline associated with a surface low in southeastern Wyoming extended southward and bulged into northwestern Kansas. Surface-based convection formed off the dryline at 2100 UTC in southwestern Kansas (Fig. 1a) prior to the nocturnal CI of interest. The convection grew upscale into a small MCS, possessing a squall-line-like structure at 2300 UTC before slowly dying out by 0500 UTC (Figs. 1b-g). The dryline began to retreat westward after 0100 UTC.

Operational forecasts from the National Weather Service (NWS) and Storm Prediction Center (SPC) predicted that storms would be unlikely to develop overnight due to a stabilizing boundary layer and the cold pool from previous convection spreading northward (NOAA 2013). However, convection formed shortly after the cold pool passage, with storms forming in northwestern Kansas by 0230 UTC (yellow circle in Fig. 1e), approximately $30 \mathrm{~min}$ after sunset. This initiation episode will be the focus of this study. The cells were originally isolated but began to merge into a mesoscale system by 0500 UTC (Fig. 1g) that produced severe hail and wind in northern Kansas. The town of Ottawa in eastern Kansas also received 1.5 in. $(3.8 \mathrm{~cm})$ of rain in $30 \mathrm{~min}$ during the later stages of the MCS (Fig. 1h). More storms initiated along both the northern and southern ends of a northwest-southeast-oriented convective line that finally fell apart in the early morning hours.

An objective analysis of MesoWest surface observations (Horel et al. 2002) reveals a cold pool in southwestern Kansas at 0100 UTC (denoted by thick black contour in Figs. 1c,d) that progressed through the region of CI by 0200 UTC (Fig. 1d). The surface temperature at Hays, Kansas (yellow star in Fig. 1d), decreased from $35^{\circ} \mathrm{C}$ at 0020 UTC to $29^{\circ} \mathrm{C}$ at 0140 UTC 25 June, likely indicating the passage of an outflow boundary. However, few observations, other than conventional surface stations and the 0000 UTC upper-air soundings, were available to analyze the cause of the $\mathrm{CI}$ in northwestern Kansas. As the mechanisms responsible for initiating convection at night often go unobserved, NWP models provide a proxy for exploring specific features that are likely important. This study thus uses modeling results to hypothesize the mechanisms that may have been responsible for generating nocturnal CI for this case.

\section{Methods}

\section{a. Model configuration}

All simulations presented utilize the Advanced Research core, version 3.6.1, of the Weather Research and Forecasting (WRF-ARW; Skamarock et al. 2008) Model. An outer domain is configured at the beginning of the simulation by downscaling the operational $\mathrm{Na}-$ tional Centers for Environmental Prediction (NCEP) Global Forecast System (GFS) analysis to a WRF domain at 0000 UTC 24 June. The outer, 12-km domain spans most of the continental United States (CONUS) (Fig. 2a; $3912 \mathrm{~km} \times 3108 \mathrm{~km}$ ) and consists of 50 eta levels. These vertical grid levels are stretched, with the tightest spacing occurring near the surface up to $2.5 \mathrm{~km}$ AGL and then gradually spreading above until the model top at $50 \mathrm{hPa}$ (Fig. 2b). To generate 40 ensemble members, random Gaussian perturbations with zero mean are added to the GFS analysis of temperature $(\sigma=0.6 \mathrm{~K})$, water vapor mixing ratio $\left(\sigma=0.9 \mathrm{~g} \mathrm{~kg}^{-1}\right)$, horizontal wind $\left(\sigma=1.9 \mathrm{~m} \mathrm{~s}^{-1}\right)$, and pressure $(\sigma=$ $0.3 \mathrm{hPa}$ ) following Torn et al. (2006) and Wang et al. (2008). GFS forecasts are similarly perturbed to provide lateral boundary conditions (LBCs) for the outer domain. After DA on the outer domain is finished (detailed in the next section), an inner, convection-allowing domain with 4-km grid spacing that spans the central Great Plains (inner box in Fig. 2a; $1384 \mathrm{~km} \times 1108 \mathrm{~km}$ ) is initialized within the outer domain. Two-way nesting is used in which forecasts from the inner domain also update the outer domain. 


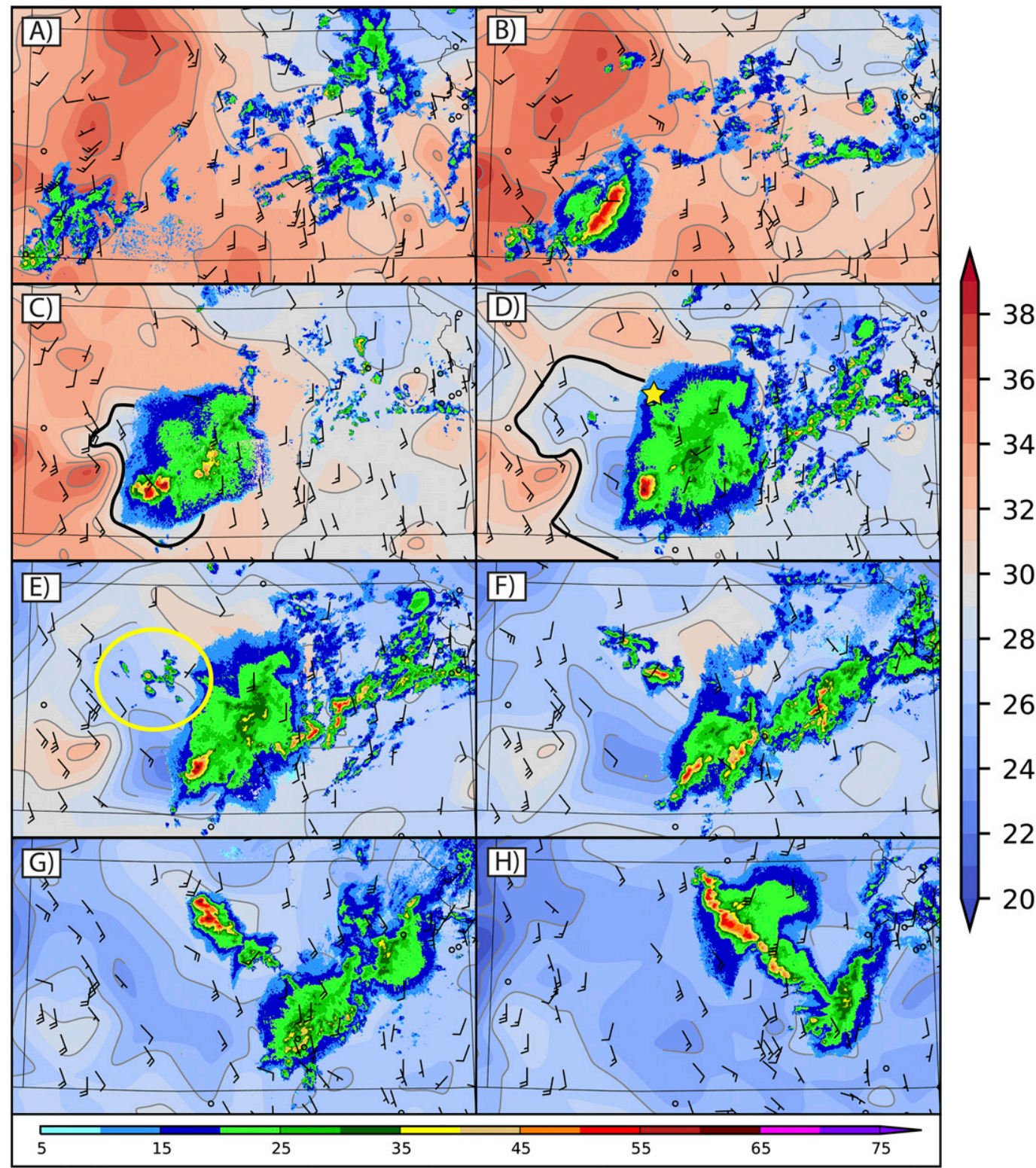

FIG. 1. Radar observations of composite reflectivity (dBZ; bottom color bar), objectively analyzed surface temperature $\left({ }^{\circ} \mathrm{C}\right.$; right color bar), and surface wind barbs (kt) valid at (a) 2100 and (b) 2300 UTC 24 Jun, and (c) 0100, (d) 0200, (e) 0230, (f) 0330, (g) 0500, and (h) 0700 UTC 25 Jun. Surface observations are obtained from the MesoWest program (Horel et al. 2002). The objective analysis is performed using a two-dimensional linear spline interpolation before applying a Gaussian smoother over a $10-\mathrm{km}$ radius. Surface temperature contours are also overlaid in solid gray lines every $2^{\circ} \mathrm{C}$. The thick black contours in (c), (d) for $31^{\circ} \mathrm{C}$ indicate the location of a cold pool discussed in the text. The yellow star in (d) indicates the location of Hays, KS. The yellow circle in (e) represents the CI of interest.

Fixed physical parameterization schemes are used for all 40 members during both the DA and forecast periods. The schemes include the Mellor-YamadaNakanishi-Niino (MYNN; Nakanishi and Niino 2006) PBL scheme and both the WRF single-moment 6-class (WSM6; Hong and Lim 2006) and Lin et al. (1983) microphysical schemes. Coniglio et al. (2013) found that although many PBL schemes perform similarly in the morning, the 1.5-order local closure MYNN scheme is nearly unbiased for evening profiles of temperature and moisture. WSM6 is utilized only during the DA cycles to be consistent with the observation operator for 

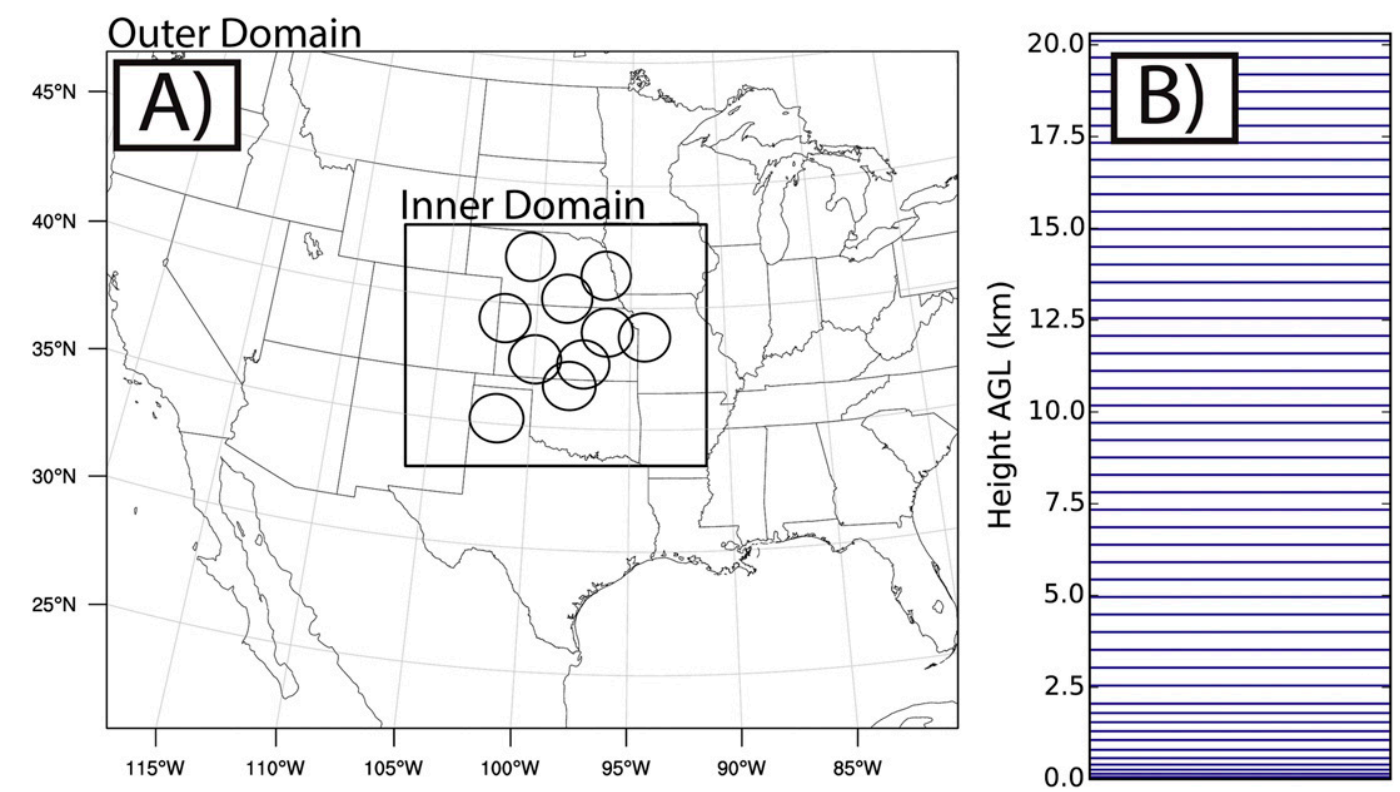

FIG. 2. Domain configurations for all simulations: (a) horizontal grid in which the outer box represents the outer, $12-\mathrm{km}$ domain, and the inner box is the convection-allowing, 4-km domain. Each circle within the inner domain represents the $150-\mathrm{km}$ radius over which a WSR-88D was assimilated. (b) Stretched vertical grid spacing for 50 eta levels in all simulations.

reflectivity (Johnson et al. 2015; Wang and Wang 2017). The Lin et al. (1983) microphysical scheme was chosen for the forecast period due to its ability to produce CI with a similar orientation and shape to that which was observed. French and Parker (2008) successfully used the Lin scheme to simulate the initiation of both supercells and an MCS in WRF. The Lin scheme has also been shown to perform well for other convective modes (e.g., Nasrollahi et al. 2012). Additional sensitivity studies were conducted using various microphysical and PBL parameterization schemes; all schemes produced $\mathrm{CI}$ at similar locations and times. The Noah land surface model (Ek et al. 2003), Rapid Radiative Transfer Model for general circulation models (longwave radiation; Iacono et al. 2008), Goddard shortwave radiation (Tao et al. 2003), and Grell-Freitas (Grell and Freitas 2014) cumulus parameterization schemes are also employed. Cumulus parameterization is turned off on the innerdomain simulations.

\section{b. Data assimilation system configuration}

The EnKF method for DA samples from ensemble forecasts to provide a flow-dependent estimate of the background error covariances (Houtekamer and Zhang 2016). An operational version of a Gridpoint Statistical Interpolation (GSI)-based hybrid EnKF-Var system is currently in use at NCEP for global forecasts (Wang et al. 2013; Wang and Lei 2014; Mahajan et al. 2017). The operational system was recently extended to assimilate reflectivity and radial velocity observations in Johnson et al. (2015) and Wang and Wang (2017). This study builds on the EnKF component of the extended system to assimilate multiscale observations, including radar and conventional in situ data, in order to understand the impact of such observations on the prediction of nocturnal CI. This study also utilizes the ensemble square root filter (EnSRF) algorithm described in Whitaker and Hamill (2002).

The data utilized include conventional in situ and radar observations. The in situ dataset contains rawinsondes, surface METAR and mesonets, in situ aircraft, NOAA wind profilers, and ship and buoy observations obtained from the North American Mesoscale Forecast System Data Assimilation System (NDAS) at the NOAA Operational Model Archive and Distribution System (NOMADS; Rutledge et al. 2006; Rogers et al. 2009). Multiple passes of quality control are performed on the dataset at NCEP, and additional gross error checks occur within GSI. The radar observations (radar reflectivity factor and radial velocity) are NEXRAD level 2 data obtained from the National Centers for Environmental Information (NCEI). The location of the WSR-88Ds that are used can be seen by the circles in Fig. 2a. We note that the KDDC radar in southwestern Kansas was offline until 0115 UTC 25 June. Thus, only three cycles of DA include data from KDDC. Before 
being assimilated, all radar data are preprocessed through the Warning Decision Support SystemIntegrated Information (WDSS-II; Lakshmanan et al. 2007) software package, where velocity data are dealiased and nonmeteorological echoes are removed. Reflectivity observations less than $5 \mathrm{~dB} Z$ are set to $-35 \mathrm{dBZ}$ within GSI to help suppress spurious convection during the DA cycles and to be consistent with the minimum reflectivity allowed in WRF. The reflectivity observation operator associated with WSM6 follows Johnson et al. $(2015 ; 2017)$, and the error of radar reflectivity and radial velocity observations are set to $5 \mathrm{dBZ}$ and $2 \mathrm{~m} \mathrm{~s}^{-1}$, respectively, following Johnson et al. (2015) and Yussouf et al. (2015).

Covariance localization uses the Gaspari and Cohn (1999) function to treat the problem of sampling errors during the estimation of ensemble covariances. A unique cutoff radius, which is vertically stretched, is set for each observation type in both the horizontal and vertical (Johnson et al. 2015). For the conventional in situ observations assimilated on the outer domain, the horizontal localization cutoff radius is set to $700 \mathrm{~km}$ and increased to $1050 \mathrm{~km}$ at the model top (Pan et al. 2014; Johnson et al. 2015). The vertical localization is set to 0.275 scale height units (natural log of pressure) and increased to 0.55 at the model top for temperature and moisture. The vertical localization is increased from 0.55 to 1.1 scale height units for wind. On the inner domain, constant correlation length scales of $20 \mathrm{~km}$ in the horizontal and 1.1 scale height units in the vertical are used for the assimilation of both radial velocity and reflectivity. When assimilating surface mesonet observations, Sobash and Stensrud (2015) found that increasing the correlation cutoff radius to $240 \mathrm{~km}$ for storm-scale predictions improved the model fit to observations but diminished the skill in CI forecasts. For in situ observations assimilated on the inner domain (mostly surface observations), the correlation length scale in the horizontal is increased to $200 \mathrm{~km}$.

To treat errors associated with the misrepresentation of background errors, inflation methods of both a constant 15\% (multiplicative; Whitaker and Hamill 2012) and a relaxation to prior spread of $95 \%$ (Whitaker and Hamill 2012) are applied to the ensemble during every DA cycle. The constant inflation parameters smoothly decrease to $\sim 3 \%$ at the model top to avoid overdispersion (Zhu et al. 2013; Johnson et al. 2015). Finally, to maintain ensemble spread and quickly introduce observed storms into the inner-domain analyses, random Gaussian noise with zero mean is added during each cycle and to every grid point for temperature $(\sigma=0.5 \mathrm{~K})$, dewpoint temperature $(\sigma=0.5 \mathrm{~K})$, and horizontal winds $\left(\sigma=0.5 \mathrm{~m} \mathrm{~s}^{-1}\right)$, following Dowell and Wicker (2009) and Wang and Wang (2017).

\section{c. Experimental design}

The simulations described in this study are multiscale, in that observations are separately assimilated on each domain to improve analyses of features resolved at their respective scales. DA on the outer, mesoscale domain acts to improve larger-scale features, such as a PV anomaly in the lee of the Rockies, whereas DA on the inner domain acts to improve convective-scale features. On the inner domain, assimilating in situ observations aids in nocturnal CI forecasts by improving convectivescale areas of instability and elevated convergence zones related to the LLJ. The assimilation of radar observations is designed to aid in analyzing ongoing convection.

We design separate DA experiments to isolate the importance of each observation type (in situ and radar) on the subsequent forecast (Table 1). To best estimate the synoptic environment, conventional in situ data are assimilated on the outer domain for each experiment from 0000 UTC 24 June until 0000 UTC 25 June, when a large number of synoptic-scale observations are available. The inner domain is then initialized at 0000 UTC 25 June, following the flowchart in Fig. 3. In the outerDA experiment, no data are assimilated on the inner domain, and the forecasts are downscaled directly from the outer-domain analysis at 0000 UTC 25 June. For the other experiments, the radar and in situ observations are assimilated at different cycling intervals to best represent the error growth time scales for each observation type. Sobash and Stensrud (2015) found little improvement in a CI forecast when extending their convective-scale assimilation of mesonet observation beyond $1 \mathrm{~h}$. Thus, in convDA, in situ observations are assimilated on the inner domain for three cycles of 30-min intervals out to 0130 UTC 25 June. In radarDA, only radar data are assimilated on the inner domain for

TABLE 1 . Summary of observation assimilation experiments on the inner domain.

\begin{tabular}{ll}
\hline \hline outerDA & No observations assimilated on the inner domain \\
convDA & Conventional in situ observations assimilated for three cycles (every 30 min) \\
radarDA & Radar observations assimilated for 18 cycles (every 5 min) \\
allDA & Both conventional in situ (three cycles; every 30 min) and radar (18 cycles; every 5 min) observations assimilated \\
\hline
\end{tabular}




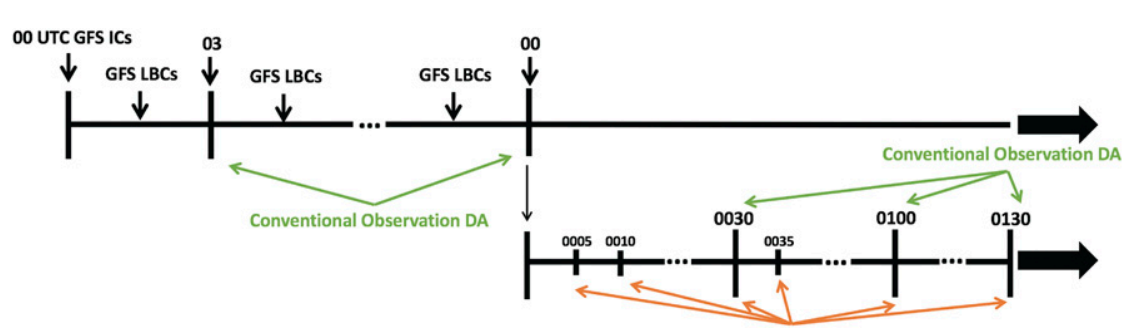

FIG. 3. Flowchart for the allDA experiment. The green arrows indicate analyses when conventional in situ observations are assimilated, and the orange lines indicate analyses when radar observations are assimilated. The top line is for the outer, 12-km domain, and the bottom line is for the inner, $4-\mathrm{km}$ domain.

18 cycles at 5-min intervals. Last, both conventional in situ and radar observations are assimilated in allDA on the inner domain with the same cycling patterns described above (Fig. 3). Although no data are assimilated on the outer domain once the inner domain is initialized, information is spread upscale through two-way nesting. Last, to save computational resources, only the first 20 analyses of the 40-member DA ensemble are used to initialize forecasts for each experiment.

\section{Observation impacts on analyses and CI forecasts}

\section{a. Impact of observations on analyses}

We first examine the impact of each observation type on the final EnKF analyses ending at 0130 UTC 25 June, $1 \mathrm{~h}$ prior to the observed CI event. The root-meansquare difference (RMSD) is calculated within the observation space to evaluate the model fit to observations. For a given ensemble mean difference of

$$
\mathbf{d}=\mathbf{y}^{o}-\overline{\mathbf{H}\left(\mathbf{x}^{b}\right)} \text { or } \mathbf{y}^{o}-\overline{\mathbf{H}\left(\mathbf{x}^{a}\right)},
$$

the RMSD is calculated as

$$
\operatorname{RMSD}=\sqrt{\left\langle\mathbf{d}^{2}\right\rangle}
$$

where $\mathbf{y}^{o}$ is the observation vector, and $\mathbf{H}\left(\mathbf{x}^{b}\right)$ or $\mathbf{H}\left(\mathbf{x}^{a}\right)$ are the background or analysis vectors in observation space, respectively. Brackets indicate an average over all observations, whereas an overbar represents an ensemble mean.

Figure 4 shows RMSD and for the inner-domain variables of temperature, water vapor mixing ratio, and wind speed averaged horizontally and vertically over the inner domain. Note that the RMSD between the analysis and the observations assimilated is only a measure of the fit to observations and is not an assessment of the analysis accuracy. Therefore, the following discussion only focuses on the background RMSD, which is evaluated over independent observations. Assimilating in situ observations on the inner domain
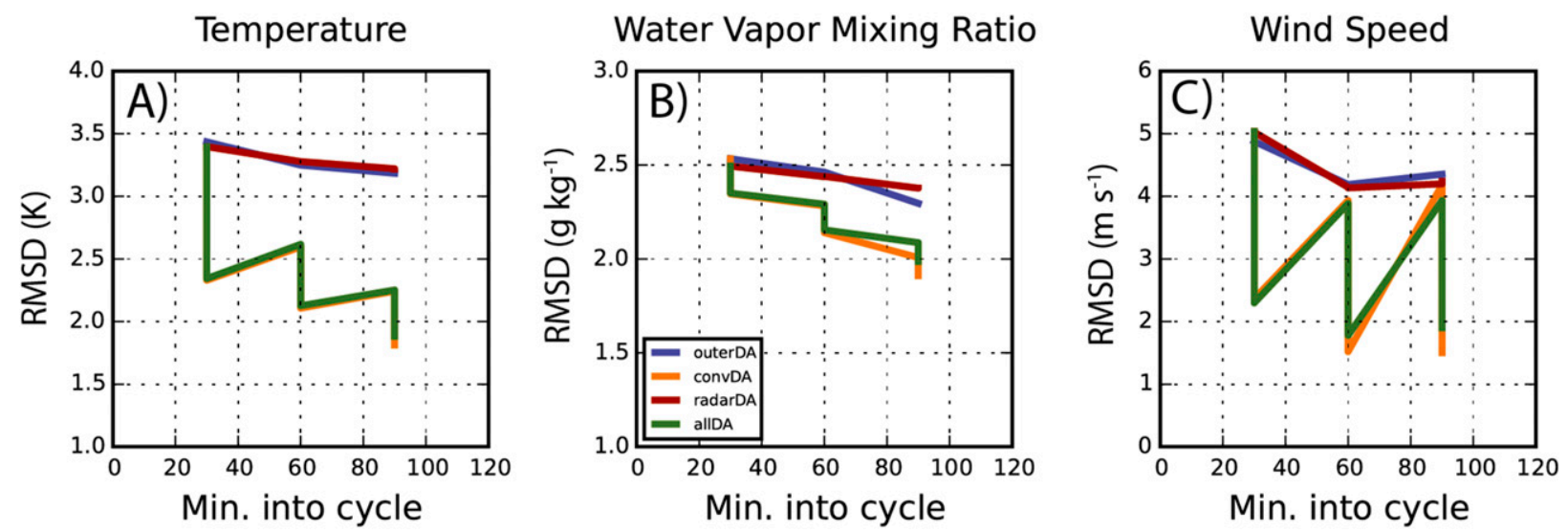

FIG. 4. Alternating time series of background and analysis RMSD (sawtooth) for the inner-domain assimilation of (a) temperature (K), (b) water vapor mixing ratio $\left(\mathrm{g} \mathrm{kg}^{-1}\right)$, and (c) wind speed $\left(\mathrm{m} \mathrm{s}^{-1}\right)$. Shown are RMSD values for outerDA (blue), convDA (orange), radarDA (red), and allDA (green). 


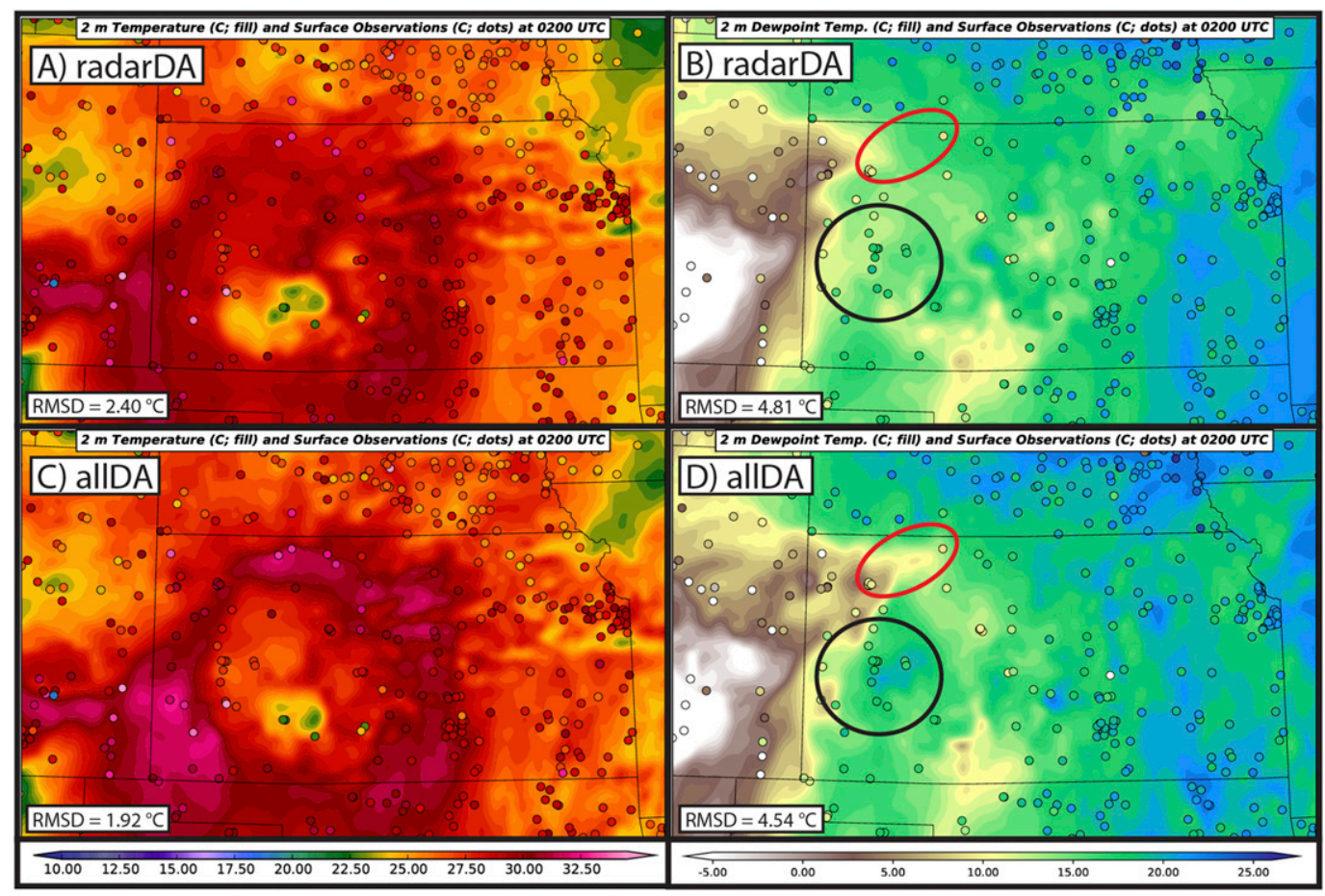

FIG. 5. Ensemble mean (a),(c) temperature $\left({ }^{\circ} \mathrm{C}\right)$ and (b), (d) dewpoint temperature $\left({ }^{\circ} \mathrm{C}\right)$ forecasts at $2 \mathrm{~m}$ AGL for (a),(b) radarDA and (c),(d) allDA, valid at 0200 UTC. Corresponding surface observations obtained from the MesoWest program (Horel et al. 2002) are overlaid as dots on the same color scale. Also shown are the RMSDs $\left({ }^{\circ} \mathrm{C}\right)$ for each plot. See text for a description of the circles.

(convDA and allDA) yields large improvements for thermodynamic variables. The first-guess temperature RMSD after $90 \mathrm{~min}$ of cycling decreases from $3.2 \mathrm{~K}$ in outerDA and radarDA to $2.3 \mathrm{~K}$ in convDA and allDA (Fig. 4a). Although the RMSD improvements for water vapor mixing ratio are smaller, the addition of in situ observations still provides an improved fit (Fig. 4b). Assimilating in situ observations also improves the model fit to wind observations, though the RMSD among all experiments is similar after a 30-min forecast (Fig. 4c). Furthermore, no discernable differences exist between the outerDA and radarDA RMSD values, indicating that the radar observations have little impact on the update of thermodynamic or kinematic variables.

Since most observations in the in situ dataset are surface observations, most of the positive impact from assimilating those observations is expected closer to the ground. We examine the impacts of assimilating in situ observations on the surface moisture and temperature analyses through a comparison of a short-term forecast (30 min) to independent observations at $0200 \mathrm{UTC}$ (Fig. 5). Only radarDA and allDA are shown to isolate the impact of assimilating in situ observations. The surface temperature forecast for radarDA is colder than the observations throughout most of Kansas, and the differences are largest to the east (Fig. 5a). Conversely, surface temperatures within a cold pool produced by convection in southwestern Kansas, and near the region of CI, are too warm in radarDA (Fig. 5a). Although cold errors still exist in allDA, surface temperatures are warmed by $1^{\circ}-2^{\circ} \mathrm{C}$ throughout much of eastern Kansas (Fig. 5c). Additionally, the northern expansion of the cold pool is improved in allDA. Assimilating in situ observations warms the surface just north of the cold pool in northwestern Kansas to more closely match the temperature gradient seen in the surface observations (Fig. 5c). Overall, the temperature RMSD at $0200 \mathrm{UTC}$ is reduced from $2.4^{\circ} \mathrm{C}$ in radarDA to $1.9^{\circ} \mathrm{C}$ in allDA.

Similar improvements can be seen in the dewpoint temperature near the surface (Figs. 5b,d). When the in situ data are assimilated, dry errors near the expansive cold pool in radarDA are generally reduced (moistened; black circles in Figs. 5b,d), and the bulging dryline further extends into northern Kansas (red circles in Figs. 5b,d). Dry errors in northeastern Kansas are also improved when assimilating in situ observations. The local-scale improvements in the cold pool and dryline structures likely contribute to the decrease in the dewpoint temperature RMSD at 0200 UTC for allDA 


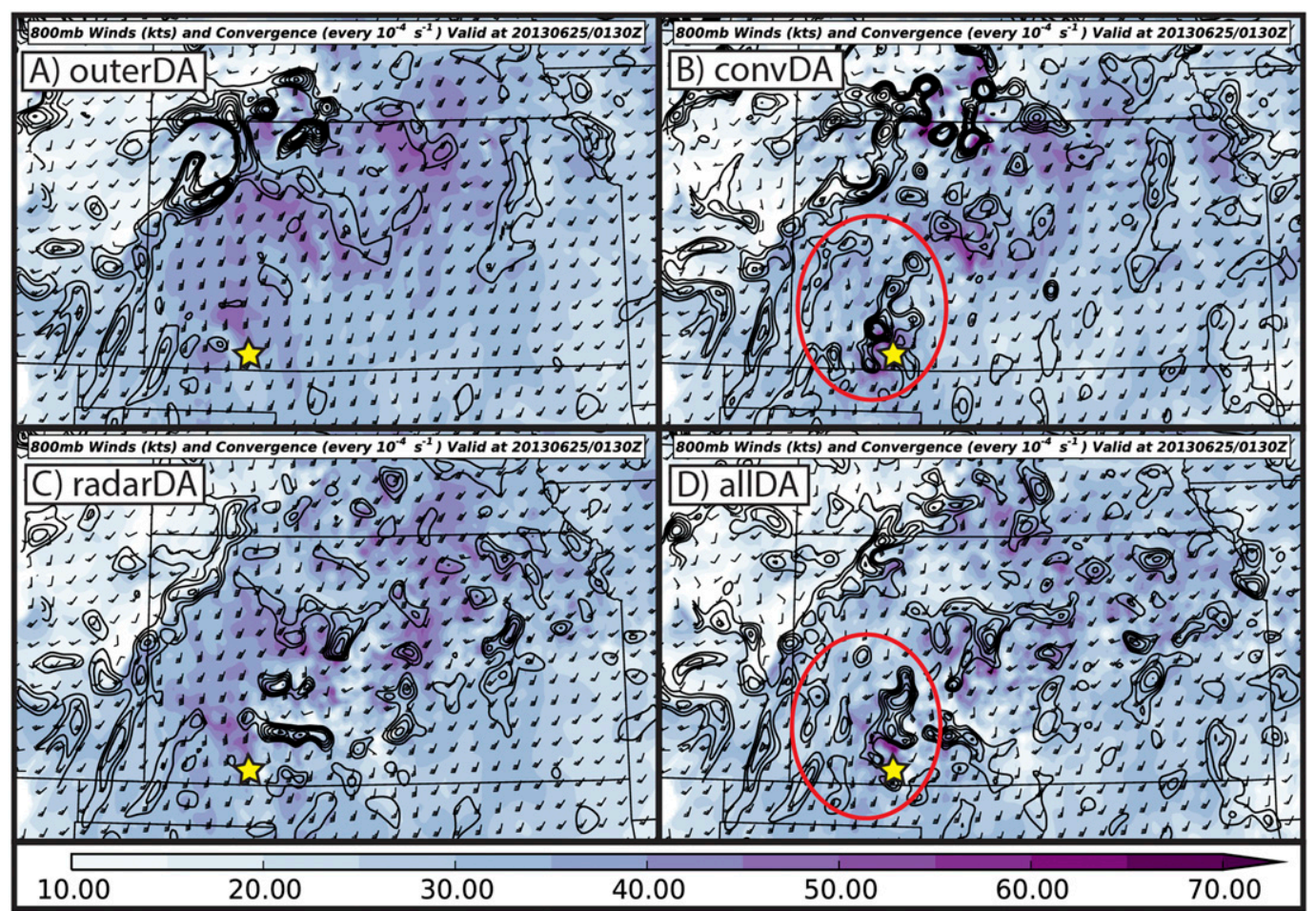

FIG. 6. Analyses of 800-hPa wind speeds (kt; fill), barbs (kt), and horizontal mass convergence (contoured every $+10^{-4} \mathrm{~s}^{-1}$ ), valid at 0130 UTC for (a) outerDA, (b) convDA, (c) radarDA, and (d) allDA member 3. The red circles highlight a region of enhanced low-level convergence introduced by conventional in situ observations in southwestern KS. The star indicates the sounding location for Fig. 7a.

$\left(4.5^{\circ} \mathrm{C}\right)$ when compared to radarDA $\left(4.8^{\circ} \mathrm{C}\right)$. Without assimilating conventional in situ observations on the inner, 4-km domain, the model cannot precisely resolve the shape and orientation of such boundaries.

Since the LLJ is known to be an important mechanism for initiating and sustaining nocturnal convection, we also examine the impacts of observations on the lowlevel wind field (Fig. 6). Without any data assimilated on the mesoscale domain, or with only radar data assimilated, wind speeds of $35-45 \mathrm{kt}\left(1 \mathrm{kt}=0.5144 \mathrm{~m} \mathrm{~s}^{-1}\right)$ are present across the western half of Kansas at $800 \mathrm{hPa}$, and mass convergence is confined to only the dryline region. Assimilating in situ observations locally weakens the wind speeds to below $25 \mathrm{kt}$ in many locations across Kansas. These regions of weaker wind speeds in convDA and allDA introduce convergence regions in southwestern Kansas (red circles in Figs. 6b,d) that are not present in outerDA or radarDA. Note that due to the smoothing effect of ensemble averaging, the convergence shown in Fig. 6 is for a single ensemble member rather than an ensemble mean.

Last, as the largest impacts from radar observations likely exist near ongoing convection, we examine the thermodynamic impacts from both observation types in southwestern Kansas (Fig. 7a; location of sounding marked by a star in Fig. 6). By weakening the ongoing convection in southwestern Kansas and reducing the amount of latent heat release, the assimilation of radar observations cools the midtroposphere and contributes to surface warming through a weaker cold pool. Radar observations also moisten the near-surface layer by approximately $1{ }^{\circ} \mathrm{C}$. Although assimilating in situ observations has an opposite thermal impact at midlevels (warming), the convDA experiment shows increased moisture in the low levels and greatly reduced CIN for parcels originating below $750 \mathrm{hPa}$ (Table 2). As mentioned previously, assimilating in situ observations improves the model fit to surface observations by warming and moistening the surface in southwestern Kansas. We hypothesize that the low-level moistening in southwestern Kansas introduced by in situ observations is related to positive ensemble correlations between the near-surface thermodynamic fields and the PBL moisture profile. However, the low-level moistening is weaker when assimilating both observation types. When both radar and in situ observations are assimilated together (allDA), the result is a profile with most unstable CAPE increased by nearly $1700 \mathrm{~J} \mathrm{~kg}^{-1}$ due to the 


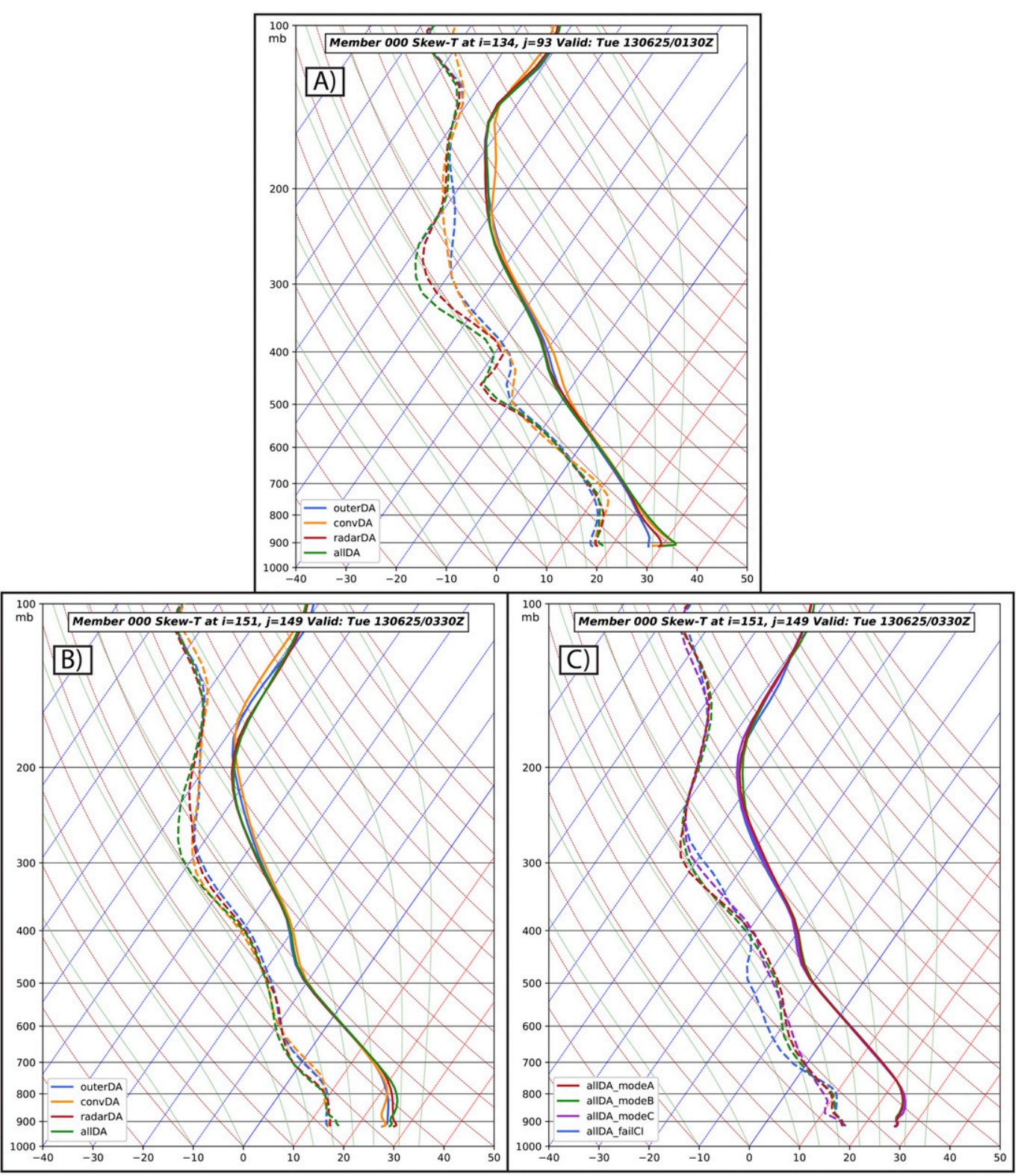

FIG. 7. Ensemble mean soundings taken in (a) southwestern KS, denoted by the star in Fig. 6 and valid at 0130 UTC, and (b) the location of CI, denoted by the blue dot in Fig. 10b and valid at 0330 UTC for outerDA (blue), convDA (orange), radarDA (red), and allDA (green). Also shown are (c) soundings at the location of CI denoted by the blue dot in Fig. 10b and valid at 0330 UTC, averaged over the members that produced the three modes of CI discussed in the text for allDA. Plotted in (c) are modes A (red), B (green), and C (purple), as well as the members that failed to produce CI (blue).

midlevel cooling and additional moistening at the surface, but with slightly higher CIN than convDA due to compounding surface warming (Table 2).

\section{b. Impact of analysis differences on CI forecasts}

To investigate reflectivity analyses and to determine which experiments produced CI, we subjectively analyze forecast differences using raw ensemble probabilities calculated with a $12-\mathrm{km}$ neighborhood (Fig. 8), following Eq. (3) from Schwartz and Sobash (2017). Without assimilating radar observations, the preexisting convective cell in southwestern Kansas is analyzed with a western bias (Figs. 8a,e). Additionally, spurious convection forms along the bulging dryline in southwestern Nebraska in outerDA and convDA and persists for many hours. When assimilating radar 
TABLE 2. Thermodynamic indices for the most unstable parcel from each experiment. The indices are valid for 0130 UTC 25 Jun and are calculated in southwestern KS, denoted by the star in Fig. 6.

\begin{tabular}{lccc}
\hline \hline Experiment & $\begin{array}{c}\text { Lifted parcel } \\
\text { level }(\mathrm{hPa})\end{array}$ & $\begin{array}{c}\text { Most unstable } \\
\text { CAPE }\left(\mathrm{J} \mathrm{kg}^{-1}\right)\end{array}$ & $\begin{array}{c}\text { Most unstable } \\
\text { CIN }\left(\mathrm{J} \mathrm{kg}^{-1}\right)\end{array}$ \\
\hline outerDA & 798 & 2003 & -102 \\
convDA & 756 & 2742 & -33 \\
radarDA & 821 & 2747 & -100 \\
allDA & 908 & 3708 & -91 \\
\hline
\end{tabular}

observations, the radarDA and allDA ensembles produce high probabilities of reflectivity greater than $30 \mathrm{~dB} Z$ for the cell in southwestern Kansas, and the storm is well analyzed (Figs. 8i,m). The spurious echoes in Nebraska are also removed from the final analyses, and later probabilities of convective development in the region are reduced in radarDA and allDA. Overall, the analyses with radar observations assimilated (Figs. 8i,m) closely match the observed $30-\mathrm{dB} Z$ echoes (black contours in Fig. 8). Although radar observations do not provide large improvements in the thermodynamic conditions, the assimilation of reflectivity data better analyzes the location of preexisting convection at 0130 UTC. Only the weaker cells in eastern Kansas (Figs. 1c,d) are missing from the radarDA and allDA analyses, as those echoes were likely too small to be correctly assimilated into the 4-km model.

By 0300 UTC (Figs. 8b,f,j,n), none of the experiments produce $\mathrm{CI}$ at its observed time in northwestern Kansas. Additionally, the analyzed cell in southwestern Kansas dissipates in radarDA and allDA, whereas the observed storm continues (Figs. 8j,n). Shortly after the analysis, widespread convection reforms just $50 \mathrm{~km}$ west of the dissipating cell in allDA (Fig. 8n). Preexisting reflectivity echoes are also enhanced in southwestern Kansas shortly after the analysis in convDA (Fig. 8f). The dissipation and subsequent reformation of the cell in allDA represents a spinup problem in which the radar observations aid in directly placing the storm into the model, but the simulation requires some adjustment

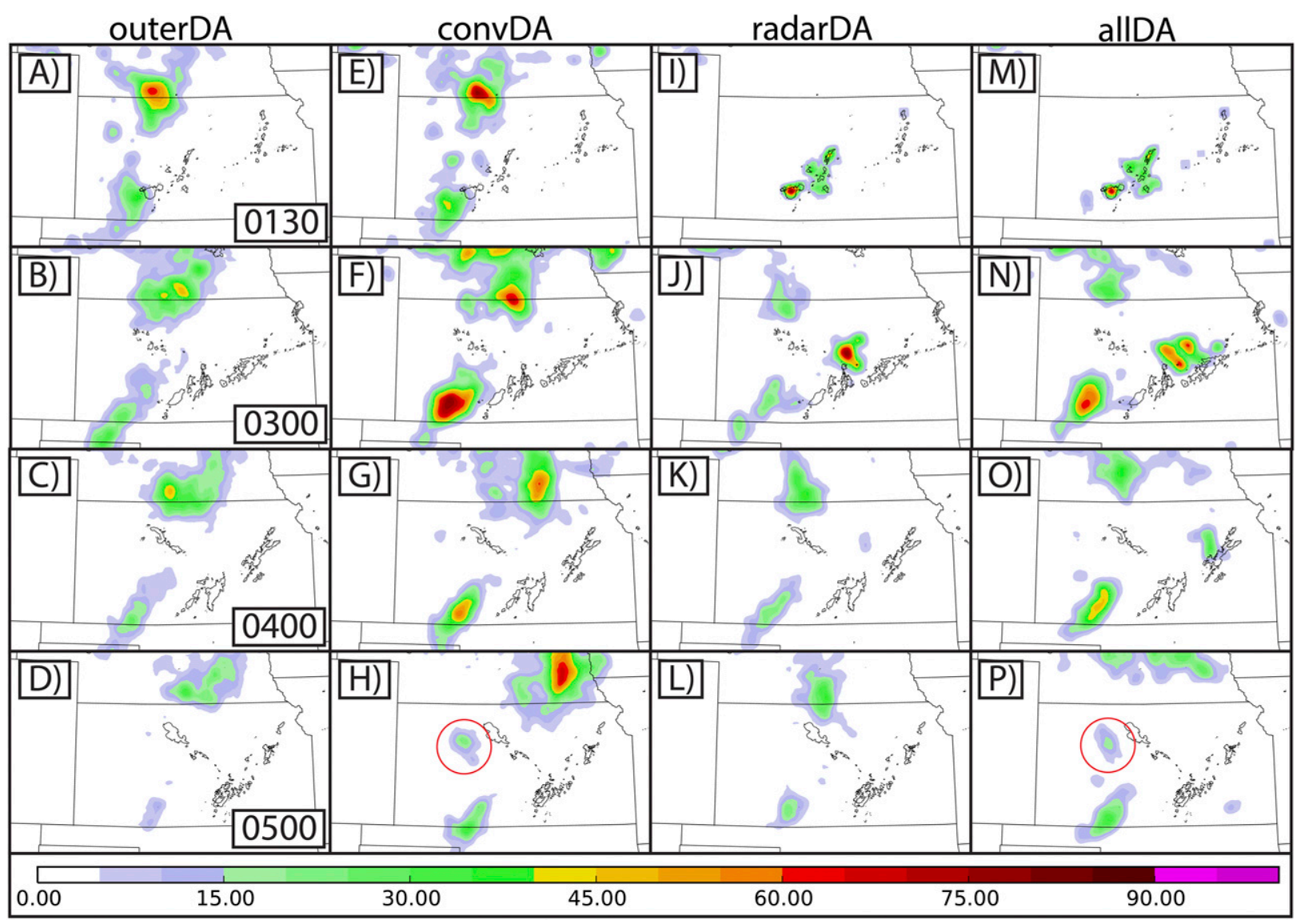

FIG. 8. Raw neighborhood ensemble probabilities (radius $=12 \mathrm{~km}$ ) of composite reflectivity greater than $30 \mathrm{~dB} Z$ for $(\mathrm{a})-(\mathrm{d})$ outerDA, (e)-(h) convDA, (i)-(l) radarDA, and (m)-(p) allDA valid at 0130, 0300, 0400, and 0500 UTC. The black contours indicate observed 30- $\mathrm{dBZ}$ composite reflectivity, and the red circles in (h),(p) indicate the successfully simulated CI of interest. 
time to be fully supportive of the convection being sustained. The downtime of KDDC in southwestern Kansas also likely contributes to the spinup problem. Similar convection does not form in outerDA (Fig. 8b), and the probability for new convection in radarDA is much lower (Fig. 8j). Thus, the assimilation of in situ observations produces a supportive environment for redeveloping convection in southwestern Kansas through both the increased convergence at $800 \mathrm{hPa}$ (Fig. 6) and the thermodynamic enhancements (Fig. 7a) discussed in the previous section.

At 0400 UTC, or $1.5 \mathrm{~h}$ after the observed CI, convDA and allDA begin to produce low ensemble probabilities $(<10 \%)$ of new convection (Figs. $8 \mathrm{~g}, \mathrm{o}) . \mathrm{CI}$ in the two experiments is more apparent by 0500 UTC and closely matches the observed orientation of CI (red circles Figs. $8 \mathrm{~h}, \mathrm{p}$ ), albeit with a western bias. No members in radarDA could produce the CI of interest in northwestern Kansas, indicating that the assimilation of in situ observations on the inner domain was important to improving the CI forecast. Three members in outerDA do simulate new convection in northern Kansas by 0500 UTC (Fig. 8d), though the convection is generated along a cold pool produced by spurious convection in southern Nebraska (mode $\mathrm{C}$, as discussed in the next section) and is not sustained at later forecast hours. The improvements from convDA to allDA are small regarding $\mathrm{CI} ; 17$ out of 20 ensemble members produce the new convection in allDA, compared to 16 in convDA. Perhaps the greatest impact provided by the addition of radar observations in allDA was the ability to better suppress strongly spurious echoes such as those in southern Nebraska.

\section{Analysis of 25 June 2013 nocturnal CI event}

\section{a. Hypothesized CI mechanisms}

To directly connect the impacts provided by the assimilation of in situ observations to the CI process, we first determine the main mechanisms leading to CI. Near the location of $\mathrm{CI}$, the four experiments produce similar temperature profiles above the PBL (Fig. 7b); the CAPE and CIN associated with elevated parcels are also relatively similar. The ensembles without conventional in situ observations assimilated are slightly moister above $650 \mathrm{hPa}$ and would reach saturation earlier if similar amounts of lifting occurred between the experiments. Considering the relatively similar thermodynamic profile between each experiment, and that outerDA and radarDA do not successfully forecast the $\mathrm{CI}$, the most important differences regarding the CI forecasts between experiments must be related to the forcing mechanisms.
Further inspection of allDA reveals three distinct modes of simulated CI based on an identification of nearby convergent boundaries (Fig. 9). In mode A (nine members), CI occurs near both the northwestern terminus of a developing LLJ in western Kansas (Fig. 9g) and a northward-progressing cold pool generated by the convection in southwestern Kansas (Fig. 9d). As previously discussed in section 2, a cold pool was observed near the CI location shortly before the first radar echo appeared. Although a weak cold pool is originally forecast in all experiments (e.g., Figs. 5a,c), a second, stronger cold pool is later produced in convDA and allDA as the convection reforms during the early simulation hours. In mode B (five members), the LLJ terminus is the only convergent boundary that appears near the new echoes (Fig. 9h). Because no significant cold pool occurs near CI as was observed, mode B is not representative of the actual CI event. Last, mode C (three members) involves $\mathrm{CI}$ at the interaction of the LLJ terminus (Fig. 9i), with a southward-progressing cold pool in northern Kansas (Fig. 9f). Mode C also could not have occurred in reality, as the cold pool is produced by spurious convection in southwestern Nebraska that was not observed. We also note that three out of the 20 ensemble members in allDA do not produce CI. An analysis of the members that fail to produce CI in allDA shows similar convergent boundaries to mode A. However, the non-CI members produce drier dewpoint temperatures in their preconvective profile by an average of $3.1^{\circ} \mathrm{C}$ between 400 and $700 \mathrm{hPa}$ prior to being lifted by the convergent boundaries (Fig. 7c). Assuming the same magnitude of ascent for the CI and non-CI simulations, the members that failed to produce $\mathrm{CI}$ would require either stronger moisture advection or additional lifting mechanisms to reach saturation.

Although the convergent boundaries are present near the location of simulated CI in allDA, their exact role in the lifting of parcels is initially unclear. To further explore the mechanisms likely responsible for CI, we analyze member 3 of mode A in allDA. Mode A is likely most representative of how CI occurred on 25 June, as it involves convection forming near a northwardprogressing cold pool as was observed. Additionally, mode A occurs for a majority of members that produce CI. Member 3 is selected, as it yields the best subjective results consistent with the structure of the observed storms (Fig. 10). Although the first echo in member 3 does not appear until 0415 UTC $(\sim 1.75 \mathrm{~h}$ after observed $\mathrm{CI}$ ), member 3 successfully forecasts the location and orientation of CI (Figs. 10b,c), as well as its evolution into a quasi-linear system (Fig. 10d). This provides confidence that the mechanisms leading to CI for this member are similar to the mechanisms responsible for 


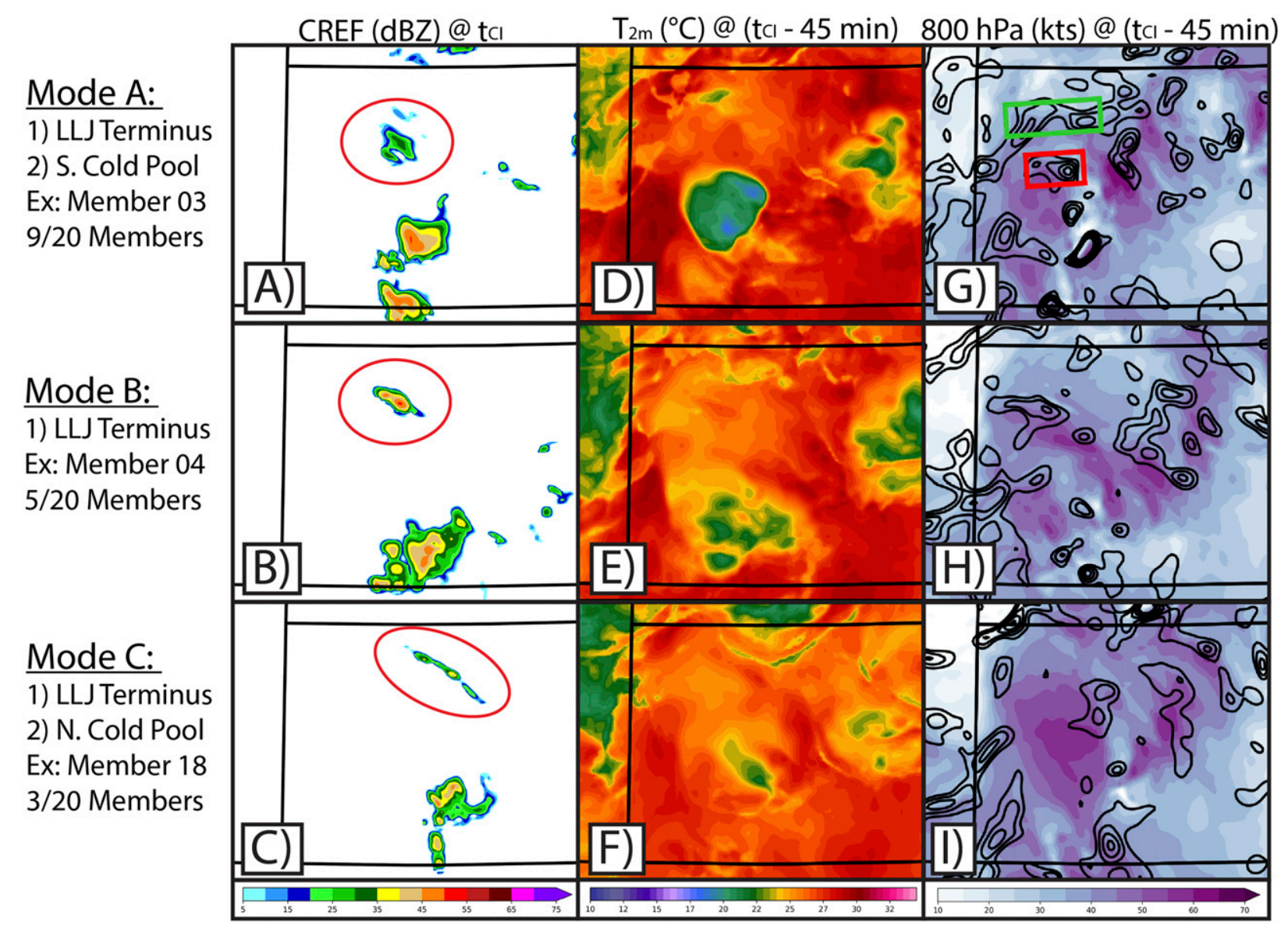

FIG. 9. Examples of the three different modes of CI simulated in allDA. Plotted for one example member from each mode are forecasts of (a)-(c) composite reflectivity valid at the time of CI; (d)-(f) temperature ( ${ }^{\circ} \mathrm{C}$ ) at $2 \mathrm{~m}$ AGL valid 45 min prior to CI; and (g)-(i) 800-hPa wind speeds (fill) and horizontal mass convergence (contoured every $+10^{-4} \mathrm{~s}^{-1}$ ) valid $45 \mathrm{~min}$ prior to CI. The mechanisms listed under each mode represent the LLJ terminus, a northern cold pool, or a southern cold pool. Note that three members of the 20-member allDA ensemble did not produce CI. The circles in (a)-(c) indicate the CI echoes, and the rectangles in (g) for allDA member 3 correspond to the regions used to compute Fig. 13.

the observed CI event. We will assume the mechanisms from member 3 as "quasi truth." We note that the analysis presented here is primarily kinematic, in that convergent boundaries are identified that likely aid in the CI process. As the exact physics responsible for CI cannot be verified without further upper-air observations, this analysis serves only as a hypothesis for the potential mechanisms responsible for the observed nocturnal CI event.

To determine the mechanisms responsible for lifting parcels to their LFC, we present a forward parcel trajectory in Figs. 10 and 11. The parcel shown was chosen owing to it rising through the updraft base at the time of CI. That parcel originates just east of the dryline at $2.1 \mathrm{~km} \mathrm{AGL}$ and is advected to the northeast following the low-level steering flow. The parcel reaches its LFC between 0415 and 0430 UTC, when it rises over $1 \mathrm{~km}$ in
$15 \mathrm{~min}$. West-east cross sections through the $y$ location of this parcel in time are presented in Fig. 11. Early on, the parcel follows the $320-\mathrm{K}$ isentrope of virtual potential temperature as it ascends through a region characterized by both warm advection and differential cyclonic vorticity advection between 500 and $800 \mathrm{hPa}$ (not shown). Solving the $\mathbf{Q}$-vector form of the quasigeostrophic omega equation (Hoskins et al. 1978) through successive overrelaxation yields vertical velocity values between 0.1 and $0.2 \mathrm{~m} \mathrm{~s}^{-1}$ along the parcel trajectory at $750 \mathrm{hPa}$. These values are similar to the parcel ascent rate of $\sim 0.25 \mathrm{~m} \mathrm{~s}^{-1}$ between 0130 and 0300 UTC (estimated through Fig. 11), suggesting that the early parcel ascent can be explained by synoptic-scale quasigeostrophic ascent. We note that the synoptic ascent is of similar sign and magnitude between all experiments and members. 


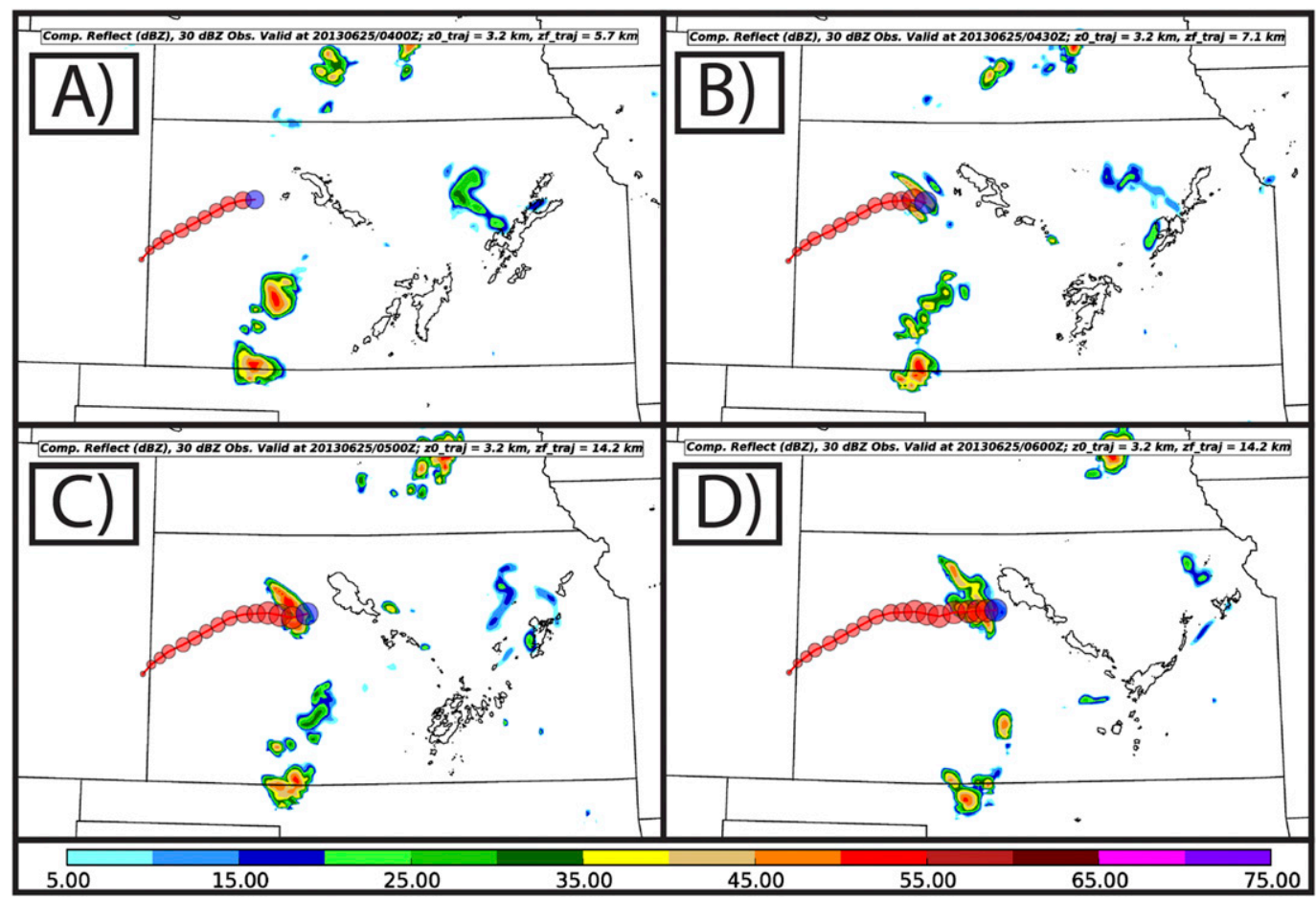

FIG. 10. Composite reflectivity forecasts for allDA member 3 valid at (a) 0400, (b) 0430, (c) 0500, and (d) 0600 UTC, with observed 30-dBZ composite reflectivity contoured in black. The red dots indicate the running forward trajectory of a parcel originating at 0130 UTC. The size of the red dots is proportional to the height AGL of the parcel.

After undergoing a period of weak descent between 0230 and 0300 UTC, the parcel begins to rise again as it encounters a band of strong ascent that extends to the tropopause (black circle in Fig. 11a). This first band of ascent contains vertical velocity values greater than $1 \mathrm{~m} \mathrm{~s}^{-1}$ and moves northwestward in opposition to the midlevel flow at $600 \mathrm{hPa}$. Between 0345 and $0400 \mathrm{UTC}$, the parcel encounters another band of positive vertical velocity (black circle in Fig. 11b) that is rooted at $\sim 1 \mathrm{~km}$ AGL and again features ascent values greater than $1 \mathrm{~m} \mathrm{~s}^{-1}$. After encountering the second band of ascent, the parcel ascends over $500 \mathrm{~m}$ in $15 \mathrm{~min}$ before

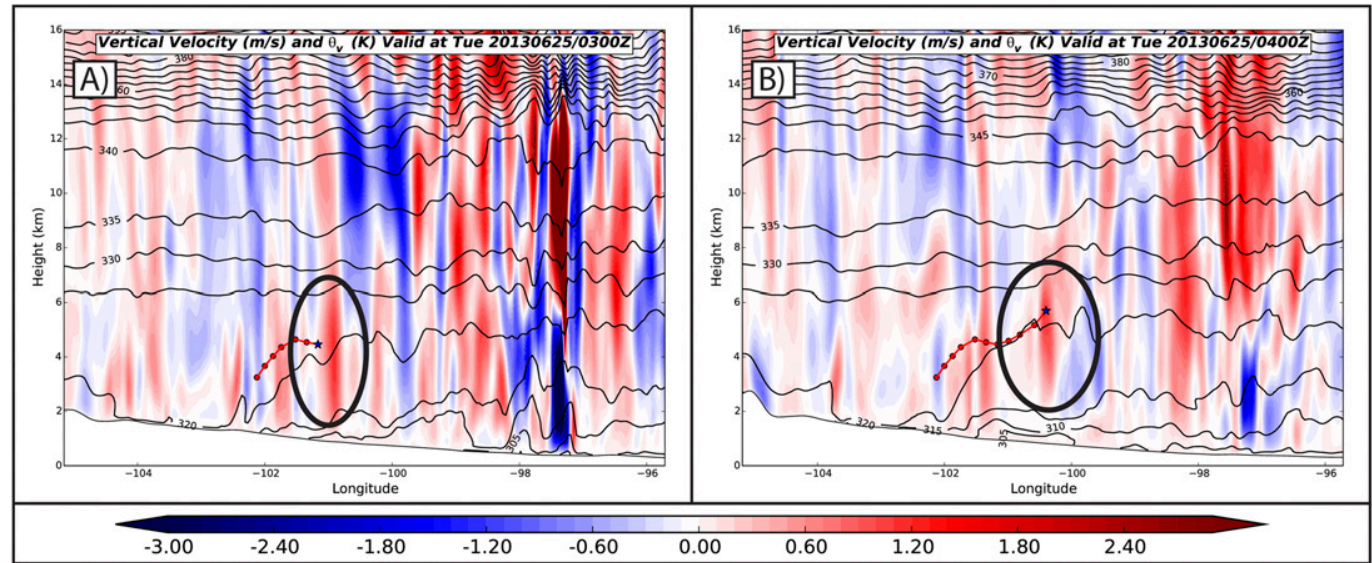

FIG. 11. East-west vertical cross sections along the parcel trajectory's location at (a) 0300 and (b) 0400 UTC for allDA member 3 . Shown are vertical velocity (fill; $\mathrm{m} \mathrm{s}^{-1}$ ) and virtual potential temperature (black contours; $\mathrm{K}$ ). The parcel trajectory is the same as the 2D trajectory in Fig. 10. See text for a description of the circles. 


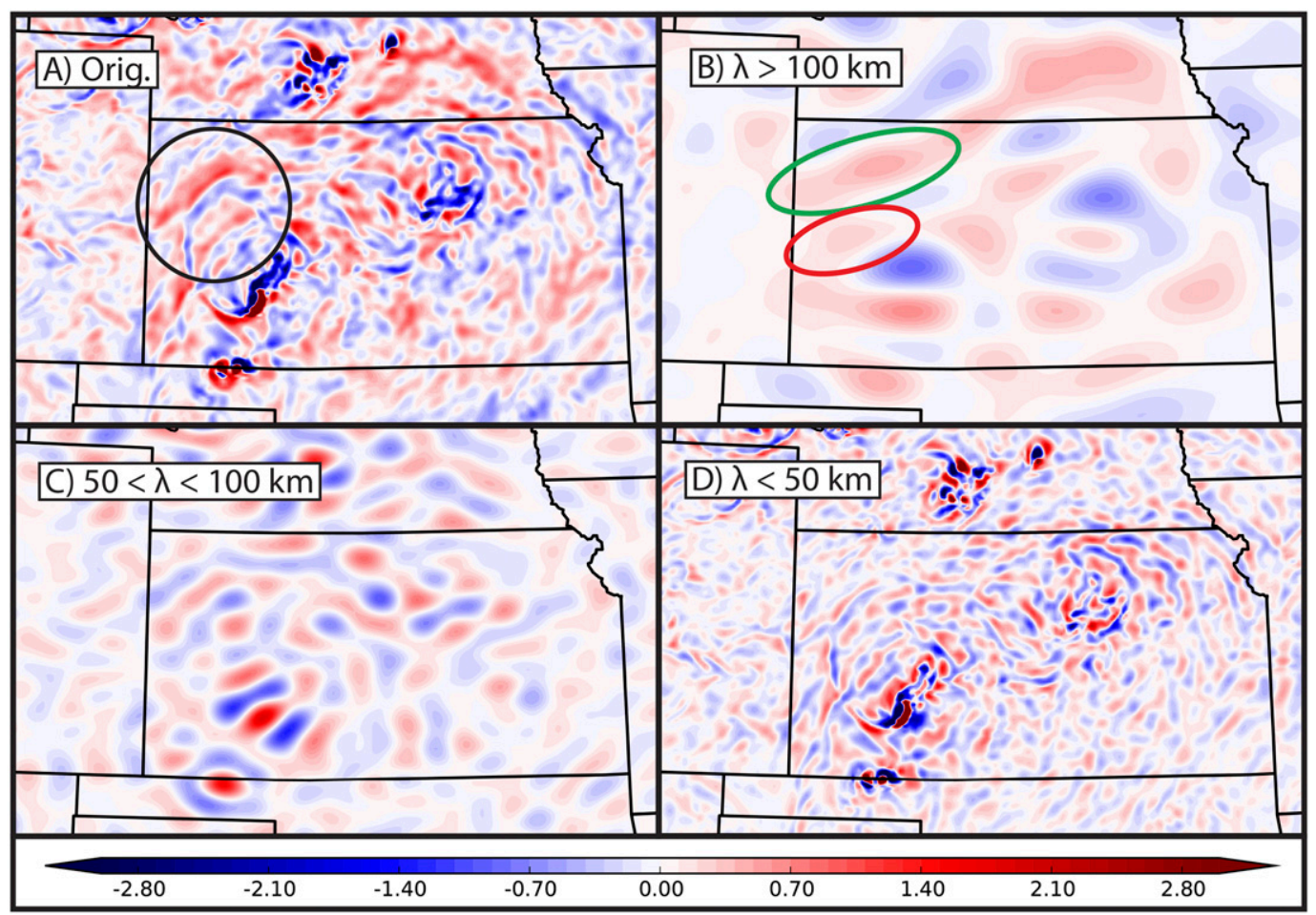

FIG. 12. Two-dimensional discrete cosine transformation of $600-\mathrm{hPa}$ vertical velocity $\left(\mathrm{m} \mathrm{s}^{-1}\right)$ valid at 0330 UTC for allDA member 3. (a) The original plot and (b) the decomposition into wavelengths greater than $100 \mathrm{~km}$, (c) between 50 and $100 \mathrm{~km}$, and (d) less than $50 \mathrm{~km}$. The circles in (b) match the regions in Fig. $9 \mathrm{~g}$.

saturating and eventually reaching its LFC. The first simulated reflectivity echoes associated with CI would appear 15 min later.

When examining the spatial extent of the two bands at $600 \mathrm{hPa}$ (circles in Fig. 12a), both appear as arcing shapes emanating from the preexisting convection in southwestern Kansas. As multiple scales of motion contribute to the full model field of vertical velocity, it is unclear whether the bands are related to cold-poolinduced gravity waves or larger, mesoscale features. To further explore the origins of the two bands of ascent, we decompose the $600-\mathrm{hPa}$ vertical velocity at 0330 UTC using a two-dimensional discrete cosine transformation (2D-DCT; Denis et al. 2002). Since the spectral variances output by the 2D-DCT are associated with the wavenumber at each grid point, the filtered physical field can be retrieved by removing certain wavenumbers and then applying a transfer function following Denis et al. (2002). We decompose the original field into three different scales: mesoscale wavelengths greater than $100 \mathrm{~km}$ (Fig. 12b), wavelengths between 50 and $100 \mathrm{~km}$ (Fig. 12c), and wavelengths less than $50 \mathrm{~km}$ (Fig. 12d).

The 2D-DCT discriminates three main mechanisms that contribute to upward motion after 0330 UTC:
1) and 2) two mesoscale features occurring at scales greater than $100 \mathrm{~km}$ (circles in Fig. 12b), and 3) gravity waves at scales less than $50 \mathrm{~km}$, as indicated by the alternating positive and negative arcs emanating from the convection in southwestern Kanas (Fig. 12d). The gravity waves appear to enhance the magnitude and provide the banded structure to the mesoscale features seen in Fig. 12b. The leading mesoscale band of ascent is collocated with the northwestern terminus of the developing LLJ in western Kansas. Between 0130 (Fig. 6d) and 0330 UTC (Fig. 9g), low-level wind speeds in western Kansas increase by $20 \mathrm{kt}$, and an east-west band of 800-hPa mass convergence becomes apparent farther north (green rectangle in Fig. 9g). The second mesoscale band of ascent is spatially and temporally correlated with the region of speed convergence produced at an outflow boundary for the northward-moving cold pool (red shapes in Figs. 9g and 12b). Since the upper-level lapse rates were steep near the preexisting convection (Fig. 7a), it is reasonable for any such lift to be vertically deep. The cold pool progresses through the region of CI at 0345 UTC, approximately $30 \mathrm{~min}$ prior to the first reflectivity echo appearing. Similarly, the observed CI episode also occurred approximately $30 \mathrm{~min}$ after passage of a cold pool (Figs. 1d,e). 


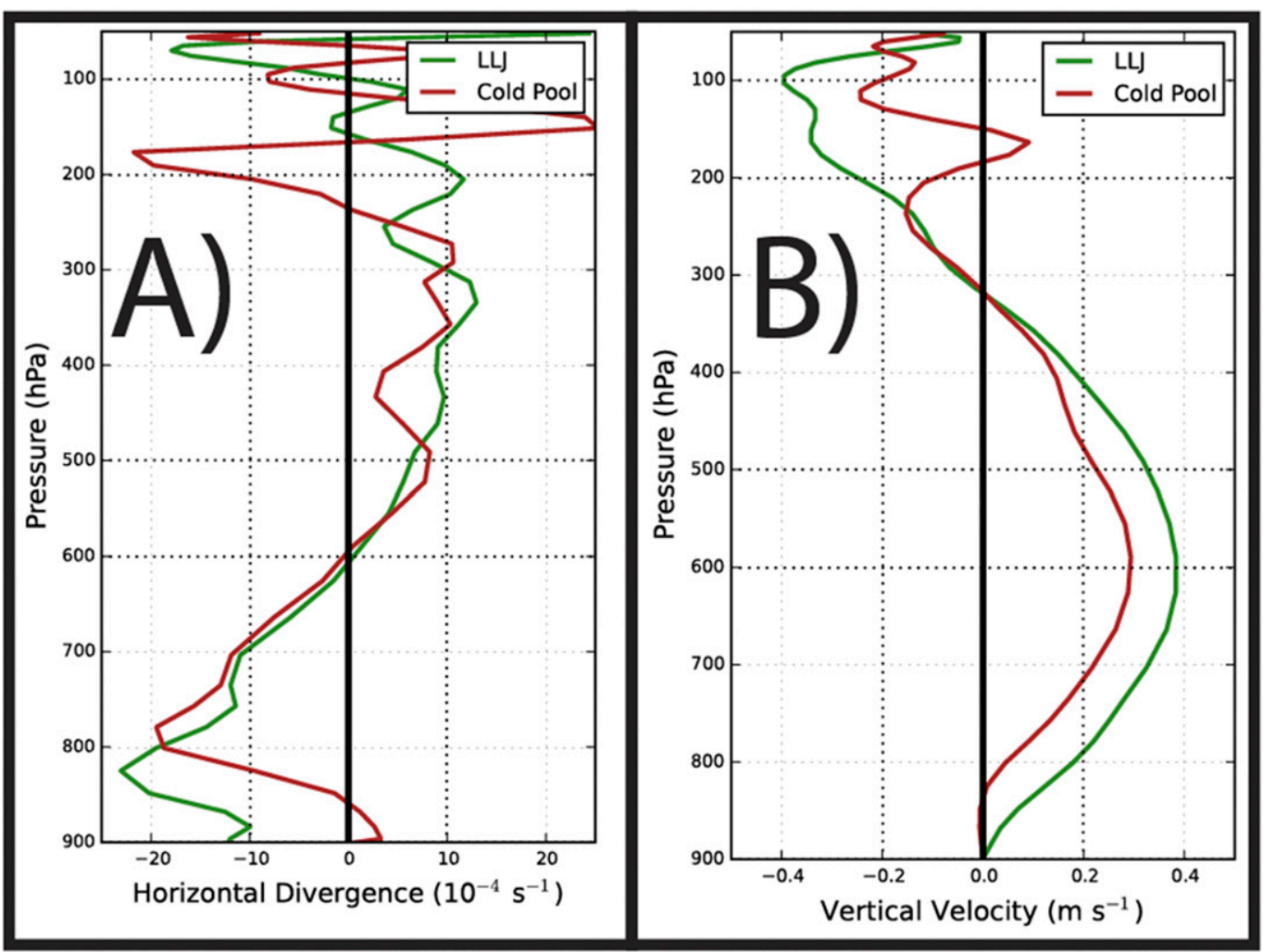

FIG. 13. Profiles of (a) horizontal mass divergence $\left(10^{-4} \mathrm{~s}^{-1}\right)$ and (b) vertical velocity $\left(\mathrm{m} \mathrm{s}^{-1}\right)$ for allDA member 3 valid at 0330 UTC. The green line is estimated from a horizontal average over the green box (LLJ terminus) in Fig. 9g; the red line is averaged over the red box (cold pool).

To further understand why the convergent boundaries described above resulted in elevated CI for this case, we make use of the incompressible form of the continuity equation to determine the impact of the ascent on a preconvective vertical profile. By estimating the ascent contributions from two specific regions of divergence, we isolate the impact of only the mesoscale mechanisms of ascent and remove influences from other features that contributed to the full model field of vertical velocity. Average profiles of divergence over the two rectangular regions in Fig. 9g are taken in Fig. 13a; the boxes are drawn to maximize the convergence at $800 \mathrm{hPa}$. Both profiles indicate deep convergence up to $600 \mathrm{hPa}$. By vertically integrating the continuity equation (assuming a no-flux upper- and lower-boundary condition: $w=0 \mathrm{~m} \mathrm{~s}^{-1}$ ), profiles of vertical velocity are estimated over those same regions (Fig. 13b). The estimated values of vertical velocity at $600 \mathrm{hPa}$ agree with the mesoscale values of ascent indicated by the 2D-DCT (Fig. 11b). Both the 2D-DCT and the continuity equation estimate $\sim 0.4 \mathrm{~m} \mathrm{~s}^{-1}$ of ascent at the LLJ terminus and $\sim 0.3 \mathrm{~m} \mathrm{~s}^{-1}$ of ascent due to the cold pool.
While the convergence produced by the mesoscale bands contributed to vertical motion consistent with the 2D-DCT and parcel trajectory, mesoscale ascent can also aid in the development of future convection by modulating the thermodynamic profile. A sounding valid 45 min before $C I$ that has been modified for the two profiles of vertical velocity is shown in Fig. 14. The onedimensional model to modify a sounding is taken from Stensrud and Maddox (1988) and only considers the effects of vertical velocity and latent heating. The governing equations are

$$
\begin{aligned}
& \frac{\partial T}{\partial t}=-w\left(\frac{T}{\theta}\right)\left(\frac{\delta \theta}{\delta z}\right)+\delta\left(\frac{L}{c_{p}}\right)\left(\frac{d q_{s}}{d t}\right), \\
& \frac{\partial q}{\partial t}=-w\left(\frac{\delta q}{\delta z}\right)-\delta\left(\frac{d q_{s}}{d t}\right),
\end{aligned}
$$

where $\delta$ is designed to maintain saturation and is defined as

$$
\delta=\left\{\begin{array}{lll}
0 & \text { if } & q \leq q_{s}, \quad d q_{s}=q-q_{s} \\
1 & \text { if } & q>q_{s}
\end{array} .\right.
$$




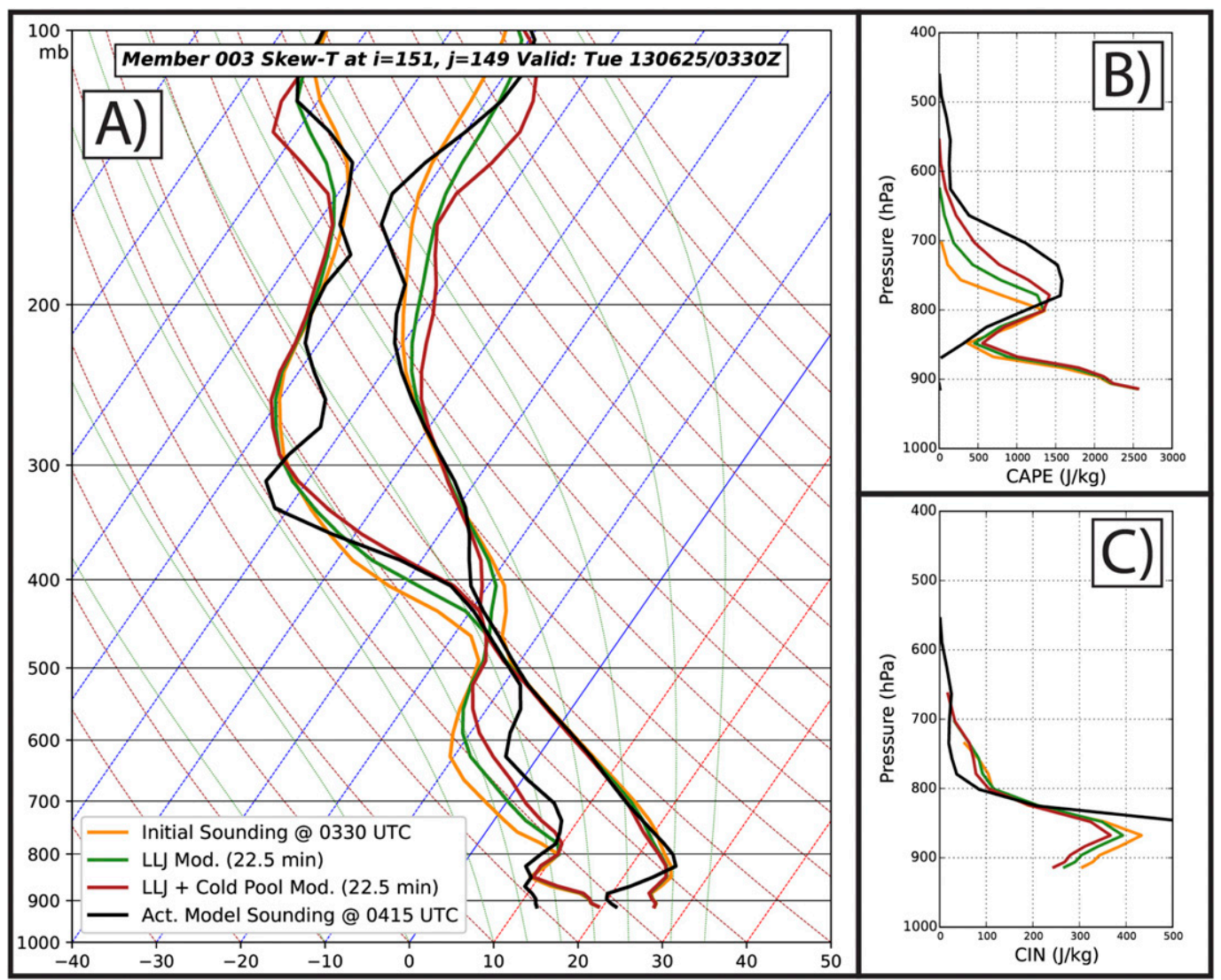

FIG. 14. Modified (a) soundings, (b) CAPE $\left(\mathrm{J} \mathrm{kg}^{-1}\right)$, and (c) CIN $\left(\mathrm{J} \mathrm{kg}^{-1}\right)$ profiles from allDA member 3 initialized at 0330 UTC from the location of CI, denoted by the blue dot in Fig. 10b. Soundings are modified following Stensrud and Maddox (1988). The initial sounding (orange) is modified for $22.5 \mathrm{~min}$ of sustained lift from the cold pool (green), which is then further modified for $22.5 \mathrm{~min}$ of additional lift from the LLJ to 0415 UTC (red). The actual model sounding valid at 0415 UTC is given in black.

Other terms include $L$ as the latent heat of condensation, $c_{p}$ as the specific heat at constant pressure, and $q_{s}$ as the saturation mixing ratio. The simple model is integrated on the model vertical grid (Fig. 2b) at the location of CI from 0330 to 0415 UTC (time of simulated CI) using a time step of $1 \mathrm{~s}$. We allow the two mesoscale features to modify the sounding for equal amounts of time, first for $22.5 \mathrm{~min}$ of lift due to the cold pool, and then an additional $22.5 \mathrm{~min}$ of lift from the LLJ terminus (Fig. 14a). The residence times were estimated by the length of time that the parcel trajectory spent within the two ascent bands in Fig. 12b.

The original sounding at 0330 UTC (orange profile) features a moist layer at $450 \mathrm{hPa}$ that becomes saturated after being lifted by the LLJ (green profile); the saturated layer deepens when being further lifted by the cold pool (red profile). Strong cooling also occurs in the upper levels from 350 to $450 \mathrm{hPa}$ when accounting for ascent from both mechanisms (Fig. 14a). CAPE is greatly increased for parcels originating between 550 and
$800 \mathrm{hPa}$ due the upper-level cooling (Fig. 14b). Additionally, both midlevel cooling and moistening between 750 and $800 \mathrm{hPa}$ contribute to a reduction in CIN by $\sim 25 \mathrm{~J} \mathrm{~kg}^{-1}$ (Fig. 14c) for parcels lifted near the base of the cold-pool-induced updraft (Fig. 13b). The modified sounding would only require slightly more lifting through either synoptic effects or gravity waves, or advection of low-level moisture by the LLJ, to produce a profile similar to the original simulation at 0415 UTC (black profile). Although the modified sounding is only an approximation of the impacts of each band, the modifications demonstrate that the lift produced by both the LLJ terminus and cold pool, in addition to their kinematic forcing, aids in reducing CIN and increasing CAPE for parcels lifted from $750 \mathrm{hPa}$.

\section{b. Impact of observations on CI mechanisms}

The previous section demonstrated that both a convergence line related to the northwestern terminus of the LLJ and a cold pool produced by convection in 


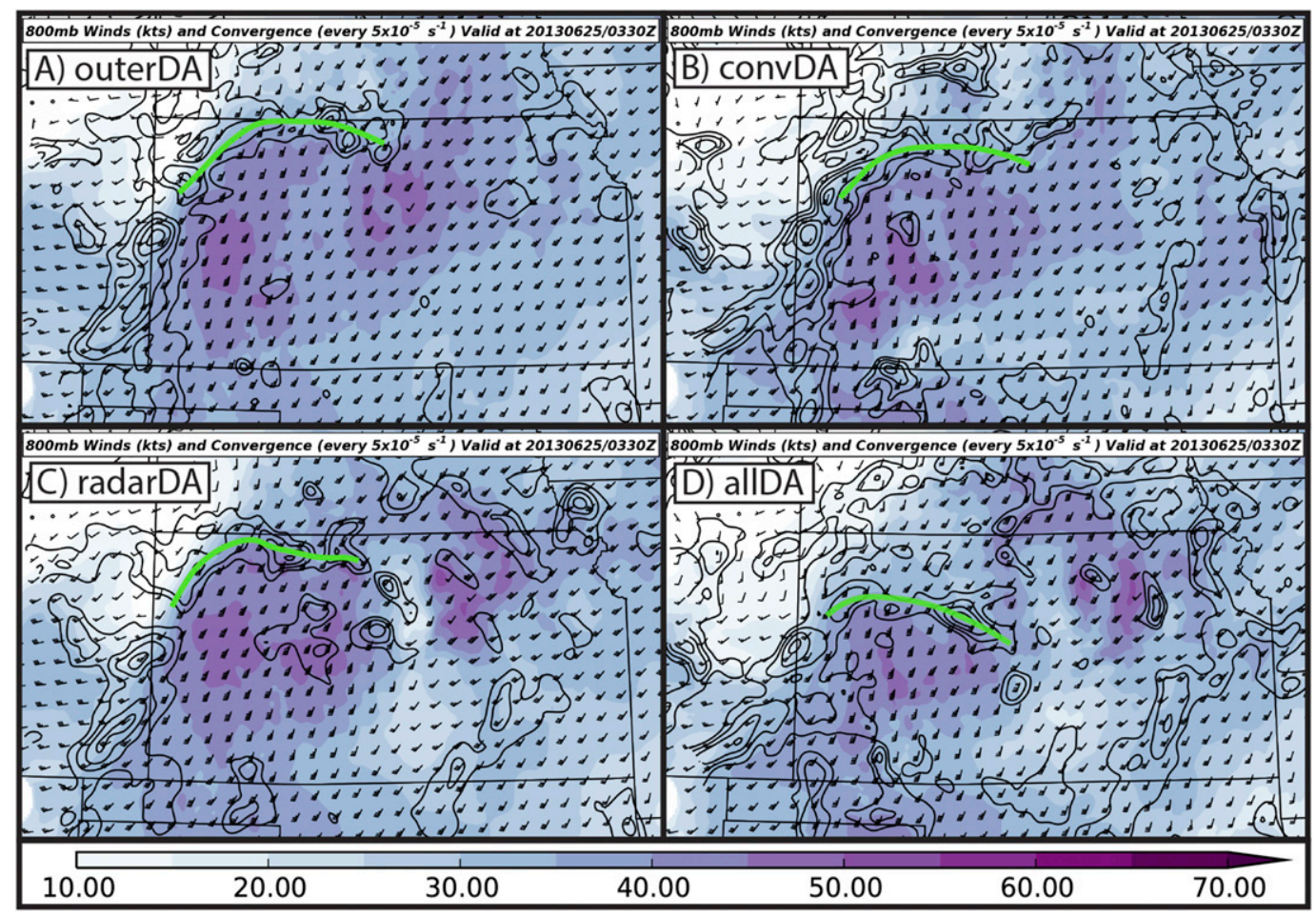

FIG. 15. As in Fig. 6, but for the ensemble mean of each experiment and valid at 0330 UTC. The contours of convergence are now shown every $+5 \times 10^{-5} \mathrm{~s}^{-1}$ to account for smoothing introduced by the ensemble mean. The green lines indicate approximate locations of the convergent bands along the LLJ terminus.

southwestern Kansas largely contribute to the nocturnal $\mathrm{CI}$ event. Without the in situ observations assimilated in outerDA and radarDA, a continuous LLJ begins to develop in western Kansas during the early evening hours (Figs. 6a,c). In convDA and allDA, low-level wind speeds are weakened during DA, and development of the LLJ is delayed (Figs. 6b,d). Although an LLJ of similar strength eventually develops for all experiments by 0330 UTC, the location of the jet terminus shifts farther south and closer to the region of CI when conventional observations are assimilated (Fig. 15b; green lines indicate convergence along LLJ terminus). The LLJ terminus is displaced even farther south in allDA (Fig. 15d), compared to convDA. An LLJ convergence band near the location of CI was seen in all successful forecast members of allDA and convDA (Figs. 9g-i), further emphasizing the importance of the feature in the CI process. Because no upper-level observations were available after 0000 UTC, the correct structure of the LLJ is unknown for this case. However, the northwestern terminus of the LLJ has been observed as a favored location for nocturnal MCS development (Kumjian et al. 2006).

The strong, northward-progressing cold pool also occurs only in experiments that assimilated in situ observations (Fig. 16). Although an earlier cold pool was observed (Fig. 1) and analyzed in both radarDA and allDA (Fig. 5), further surface cooling is produced in convDA and allDA (Figs. 16b,d) due to the enhanced convection in southwestern Kansas. Without the assimilation of in situ observations, less cooling is produced after 0300 UTC due to the weaker convection dissipating shortly after the analysis. With almost no cold pool present after 0330 UTC (Figs. 16a,c), little forcing for deep ascent exists to help parcels reach their LFC in outerDA and radarDA. As discussed in section 2, a northward-moving cold pool was observed near the location of CI approximately $30 \mathrm{~min}$ prior to initiation, supporting the hypothesis that an outflow boundary was involved in the CI process. We also found that the location of the simulated cold pool largely modulates the location of CI within mode A. The members of allDA that simulate a cold pool farther south also produce CI to the south (not shown). Thus, the cold pool was likely one of the primary mechanisms contributing to CI both in the simulations and in the actual event. As convDA and allDA simulate CI with a 1-h lag and a westward bias of $\sim 100 \mathrm{~km}$, we hypothesize that the forecast delay was partially related to the delayed spinup for the analyzed cell in southwestern Kansas discussed in 


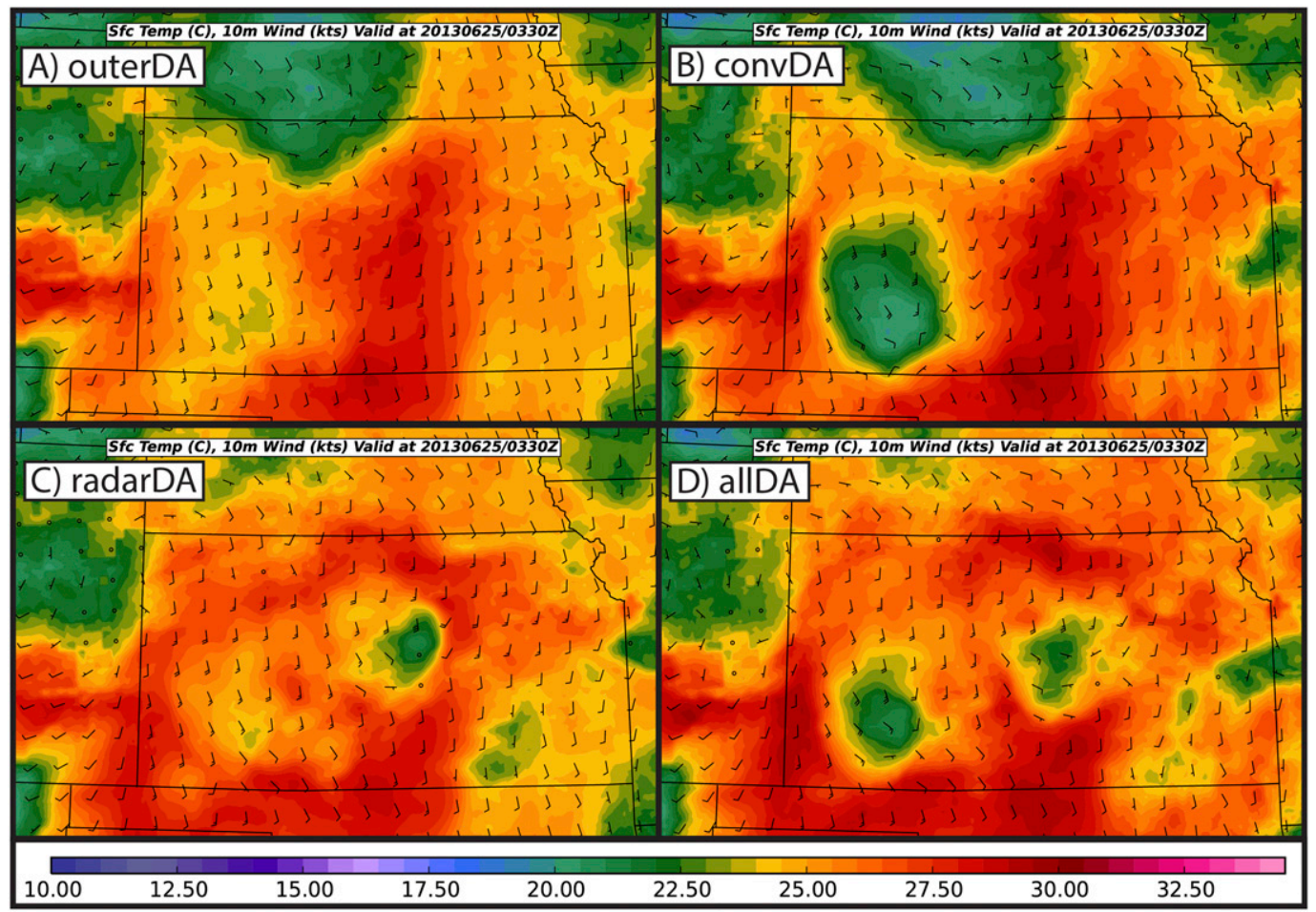

FIG. 16. Forecasts of ensemble mean temperature $\left({ }^{\circ} \mathrm{C}\right)$ at $2 \mathrm{~m}$ AGL and wind barbs $(\mathrm{kt})$ at $10 \mathrm{~m}$ AGL valid at 0330 UTC for (a) outerDA, (b) convDA, (c) radarDA, and (d) allDA.

section $4 \mathrm{~b}$. If the storm would not have dissipated in the early forecast hours, the original cold pool, combined with the developing LLJ, might have been strong enough to overcome the strong inhibition (Fig. 14) and generate $\mathrm{CI}$ at the observed time.

Gravity waves are also present in the smaller 2D-DCT wavelengths (Fig. 12d) for allDA member 3. The environment near the cold pool is favorable for gravity wave propagation due to a nearly dry adiabatic layer above a surface-based stable layer (Fig. 7b). A trapping layer for internal gravity wave propagation is produced by strong curvature in the vertical wind profile related to the LLJ that leads to negative layers of the Scorer (1949) parameter (not shown). These gravity waves would likely not form without the perturbation provided by the cold pool, as the waves are not seen in the outerDA or radarDA experiments. Thus, any additional, smaller-scale contributions to ascent are also an indirect result of assimilating the in situ observations.

Finally, we note that convDA, outerDA, and three members in allDA produce a northern cold pool (Figs. 16a,b,d) from spurious convection in Nebraska (Figs. 8c,g,o). More members were found to have produced $\mathrm{CI}$ through mode $\mathrm{C}$ (interaction of northern cold pool and LLJ) in convDA than allDA, which could not have occurred due to the spurious nature of the
Nebraska convection. Therefore, assimilating radar observations provides an improvement through the suppression of convection and its associated spurious cold pool that could lead to incorrect forecasts of CI.

\section{Conclusions}

Nocturnal CI is often difficult to forecast, both in NWP models and by skilled human forecasters. On 25 June 2013, a nocturnal CI event occurred with little warning from operational forecasts. By using an advanced multiscale DA system, positive impact was found in ensemble forecasts that assimilated both conventional in situ and radar observations for this event. A successful CI forecast occurred only in experiments that assimilated in situ observations on the inner domain. In situ observations, even though they are mostly located at the surface after 0000 UTC, were shown to improve the mesoscale environment for this event. The assimilation of in situ data reduced CIN, enhanced CAPE, and increased low-level convergence in southern Kansas. These modifications redeveloped preexisting convection in southwestern Kansas during the early forecast hours, while the same storms dissipated without the assimilation of in situ observations. Additionally, the assimilation of in situ observations weakened the low-level 
winds in western Kansas, delaying the development of an LLJ and shifting the terminus farther south.

Although an initial inspection of the nocturnal convective event shows the likely influence of a cold pool on CI, our simulations demonstrate that the developing LLJ was also involved in the CI process. Both the convergence along the LLJ terminus and the cold pool produced by the enhanced convection in southwestern Kansas were important in lifting parcels to their LFC. Without the assimilation of in situ observations, these two primary initiation mechanisms were not captured. Prior studies found positive results regarding systematic forecasts of nocturnal convection by only assimilating radar observations on a convection-permitting domain (Johnson and Wang 2017; Johnson et al. 2017). However, this study also highlights the importance of assimilating in situ observations. The fact that the successful CI forecasts resulted only when the conventional in situ observations were assimilated suggests that accurately capturing the preconvective environment and specific mesoscale features (cold pool, LLJ, etc.) is especially important for nocturnal CI forecasts.

Though assimilating only radar observations on the inner domain was not enough to capture the CI, it provided improvements by better resolving earlier convection during the forecast period and by reducing the amount of spurious precipitation in other parts of the domain. Without radar observations assimilated, many members in convDA initiated convection along a cold pool generated by spurious convection. From an operational forecaster's point of view, observing a better analysis of current ongoing convection and less spurious storms would provide more confidence in the early forecast hours of an NWP simulation. It is also likely that the use of radar DA in other cases will be important to analyze preexisting convection and any associated outflow boundaries that are responsible for subsequent CI.

Although the impact of observations is likely to be case and mechanism dependent, this study only examined the sensitivity of a single nocturnal convective event. Because nocturnal convection can be initiated by myriad other mechanisms, including gravity waves and bores, future studies should explore DA impacts for a variety of cases. Additionally, the kinematic mechanisms discussed in this paper only serve as hypotheses for the true processes leading to CI on 25 June 2013. Without high-frequency upper-air observations, it is difficult to confirm the true mechanisms responsible for CI. Only the cold pool, which was observed $30 \mathrm{~min}$ prior to CI, could be partially verified. The PECAN (Geerts et al. 2017) field experiment took place during 2015 to better understand nocturnal precipitation in the southern Great Plains. Observations from PECAN will provide dense datasets for verifying the mechanisms responsible for convection at night. As nocturnal convection is often elevated and initiated by features located above the surface, the assimilation of unique thermodynamic and kinematic observations collected during PECAN (e.g., radiometers, Doppler lidars, and wind profilers) can also provide key information for estimating such environments. Future work will examine the impact of assimilating these unique observation sets.

Since nocturnal convection can be initiated by many different mechanisms, further work will be performed to determine optimal model configurations for the specific purpose of forecasting nocturnal CI. Johnson et al. (2017) found that atmospheric bores, which are common at night and are capable of lifting air to its LFC (Haghi et al. 2017), are produced but not fully resolved in a $4-\mathrm{km}$ simulation. Though the 4-km horizontal grid spacing and 50 vertical levels were sufficient enough to produce $\mathrm{CI}$ in this case, many mechanisms that are responsible for nocturnal CI likely occur on much smaller scales. Detailed work will be required to find the optimal resolution to resolve the multiscale features responsible for initiating convection at night.

Acknowledgments. The work is primarily supported by NSF Award AGS-1359703. This work used the Yellowstone machine (ark://85065/d7wd3xhc) at NCAR's Computational and Information Systems Laboratory (CISL), sponsored by NSF. Some computing for this project also utilized the Boomer machine at the OU Supercomputing Center for Education and Research (OSCER). This study was also made possible in part due to the data made available by the governmental agencies, commercial firms, and educational institutions participating in MesoWest.

\section{REFERENCES}

Aksoy, A., D. C. Dowell, and C. Snyder, 2009: A multicase comparative assessment of the ensemble Kalman filter for assimilation of radar observations. Part I: Storm-scale analyses. Mon. Wea. Rev., 137, 1805-1824, https://doi.org/10.1175/ 2008MWR2691.1.

Augustine, J. A., and F. Caracena, 1994: Lower-tropospheric precursors to nocturnal MCS development over the central United States. Wea. Forecasting, 9, 116-135, https://doi.org/ 10.1175/1520-0434(1994)009<0116:LTPTNM>2.0.CO;2.

Bodine, D. J., and K. L. Rasmussen, 2017: Evolution of mesoscale convective system organizational structure and convective line propagation. Mon. Wea. Rev., 145, 3419-3440, https://doi.org/ 10.1175/MWR-D-16-0406.1.

Carbone, R. E., and J. D. Tuttle, 2008: Rainfall occurrence in the U.S. warm season: The diurnal cycle. J. Climate, 21, 41324146, https://doi.org/10.1175/2008JCLI2275.1. 
,,-- D. A. Ahijevych, and S. B. Trier, 2002: Inferences of predictability associated with warm season precipitation episodes. J. Atmos. Sci., 59, 2033-2056, https://doi.org/10.1175/ 1520-0469(2002)059<2033:IOPAWW>2.0.CO;2.

Childs, P. P., A. L. Qureshi, S. Raman, K. Alapaty, R. Ellis, R. Boyles, and D. Niyogi, 2006: Simulation of convective initiation during IHOP_2002 using the Flux-Adjusting Surface Data Assimilation System (FASDAS). Mon. Wea. Rev., 134, 134-148, https://doi.org/10.1175/MWR3064.1.

Coniglio, M. C., J. Correia Jr., P. T. Marsh, and F. Kong, 2013: Verification of convection- allowing WRF Model forecasts of the planetary boundary layer using sounding observations. Wea. Forecasting, 28, 842-862, https://doi.org/10.1175/ WAF-D-12-00103.1.

Corfidi, S. F., S. J. Corfidi, and D. M. Schultz, 2008: Elevated convection and castellanus: Ambiguities, significance, and questions. Wea. Forecasting, 23, 1280-1303, https://doi.org/ 10.1175/2008WAF2222118.1.

Davis, C. A., K. W. Manning, R. E. Carbone, S. B. Trier, and J. D. Tuttle, 2003: Coherence of warm-season continental rainfall in numerical weather prediction models. Mon. Wea. Rev., 131, 2667-2679, https://doi.org/10.1175/1520-0493(2003)131<2667: COWCRI $>2.0 . \mathrm{CO} ; 2$.

Denis, B., J. Côté, and R. Laprise, 2002: Spectral decomposition of two-dimensional atmospheric fields on limited-area domains using the discrete cosine transform (DCT). Mon. Wea. Rev., 130, 1812-1829, https://doi.org/10.1175/1520-0493(2002) $130<1812:$ SDOTDA $>2.0 . \mathrm{CO} ; 2$.

Dowell, D. C., and L. J. Wicker, 2009: Additive noise for stormscale ensemble data assimilation. J. Atmos. Oceanic Technol., 26, 911-927, https://doi.org/10.1175/2008JTECHA1156.1.

Ek, M., K. Mitchell, Y. Lin, E. Rogers, P. Grunmann, V. Koren, G. Gayno, and J. Tarpley, 2003: Implementation of Noah land surface model advances in the National Centers for Environmental Prediction operational mesoscale Eta model. J. Geophys. Res., 108, 8851, https://doi.org/10.1029/ 2002JD003296.

Fabry, F., 2006: The spatial variability of moisture in the boundary layer and its effect on convection initiation: Project-long characterization. Mon. Wea. Rev., 134, 79-91, https://doi.org/ 10.1175/MWR3055.1.

French, A. J., and M. D. Parker, 2008: The initiation and evolution of multiple modes of convection within a meso-alpha-scale region. Wea. Forecasting, 23, 1221-1252, https://doi.org/ 10.1175/2008WAF2222136.1.

Fritsch, J. M., and R. E. Carbone, 2004: Improving quantitative precipitation forecasts in the warm season: A USWRP research and development strategy. Bull. Amer. Meteor. Soc., 85 , 955-966, https://doi.org/10.1175/BAMS-85-7-955.

Gaspari, G., and S. E. Cohn, 1999: Construction of correlation functions in two and three dimensions. Quart. J. Roy. Meteor. Soc., 125, 723-757, https://doi.org/10.1002/qj.49712555417.

Geerts, B., and Coauthors, 2017: The 2015 Plains Elevated Convection at Night (PECAN) field project. Bull. Amer. Meteor. Soc., 98, 767-786, https://doi.org/10.1175/BAMS-D-15-00257.1.

Glickman, T. S., Ed., 2000: Glossary of Meteorology. 2nd ed. Amer. Meteor. Soc., 855 pp., http://glossary.ametsoc.org/.

Grell, G. A., and S. R. Freitas, 2014: A scale and aerosol aware stochastic convective parameterization for weather and air quality modeling. Atmos. Chem. Phys., 14, 5233-5250, https:// doi.org/10.5194/acpd-13-23845-2013.

Haghi, K. R., D. B. Parsons, and A. Shapiro, 2017: Bores observed during IHOP_2002: The relationship of bores to the nocturnal environment. Mon. Wea. Rev., 145, 3929-3946, https://doi.org/ 10.1175/MWR-D-16-0415.1.

Helfand, H., and S. D. Schubert, 1995: Climatology of the simulated Great Plains low-level jet and its contribution to the continental moisture budget of the United States. J. Climate, $\mathbf{8}$, 784-806, https://doi.org/10.1175/1520-0442(1995)008<0784: COTSGP $>2.0 . \mathrm{CO} ; 2$.

Higgins, R., Y. Yao, E. Yarosh, J. E. Janowiak, and K. Mo, 1997: Influence of the Great Plains low-level jet on summertime precipitation and moisture transport over the central United States. J. Climate, 10, 481-507, https://doi.org/10.1175/ 1520-0442(1997)010<0481:IOTGPL > 2.0.CO;2.

Hong, S., and J. J. Lim, 2006: The WRF single-moment 6-class microphysics scheme (WSM6). J. Korean Meteor. Soc., 42, 129-151.

Horel, J., and Coauthors, 2002: MesoWest: Cooperative mesonets in the western United States. Bull. Amer. Meteor. Soc., 83, 211-226, https://doi.org/10.1175/1520-0477(2002)083<0211: MCMITW $>2.3 . \mathrm{CO} ; 2$.

Horgan, K. L., D. M. Schultz, J. E. Hales, S. F. Corfidi, and R. H. Johns, 2007: A five-year climatology of elevated severe convective storms in the United States east of the Rocky Mountains. Wea. Forecasting, 22, 1031-1044, https://doi.org/10.1175/ WAF1032.1.

Hoskins, B. J., I. Draghici, and H. C. Davies, 1978: A new look at the $w$-equation. Quart. J. Roy. Meteor. Soc., 104,31-38, https:// doi.org/10.1002/qj.49710443903.

Houtekamer, P. L., and F. Zhang, 2016: Review of the ensemble Kalman filter for atmospheric data assimilation. Mon. Wea. Rev., 144, 4489-4532, https://doi.org/10.1175/MWR-D-150440.1

Iacono, M. J., J. S. Delamere, E. J. Mlawer, M. W. Shephard, S. A. Clough, and W. D. Collins, 2008: Radiative forcing by longlived greenhouse gases: Calculations with the AER radiative transfer models. J. Geophys. Res., 113, D13103, https://doi.org/ 10.1029/2008JD009944.

Johnson, A., and X. Wang, 2017: Design and implementation of a GSI-based convection- allowing ensemble data assimilation and forecast system for the PECAN field experiment. Part I: Optimal configurations for nocturnal convection prediction using retrospective cases. Wea. Forecasting, 32, 289-315, https://doi.org/10.1175/WAF-D-16-0102.1.

, — J. R. Carley, L. J. Wicker, and C. Karstens, 2015: A comparison of multiscale GSI-based EnKF and 3DVar data assimilation using radar and conventional observations for midlatitude convective-scale precipitation forecasts. Mon. Wea. Rev., 143, 3087-3108, https://doi.org/10.1175/MWR-D14-00345.1.

—, _, and S. K. Degelia, 2017: Design and implementation of a GSI-based convection-allowing ensemble data assimilation and forecast system for the PECAN field experiment. Part II: Overview and evaluation of a real-time system. Wea. Forecasting, 32, 1227-1251, https://doi.org/10.1175/WAF-D16-0201.1.

Jones, T. A., D. Stensrud, L. Wicker, P. Minnis, and R. Palikonda, 2015: Simultaneous radar and satellite data storm-scale assimilation using an ensemble Kalman filter approach for 24 May 2011. Mon. Wea. Rev., 143, 165-194, https://doi.org/ 10.1175/MWR-D-14-00180.1.

Kain, J. S., and Coauthors, 2013: A feasibility study for probabilistic convection initiation forecasts based on explicit numerical guidance. Bull. Amer. Meteor. Soc., 94, 1213-1225, https:// doi.org/10.1175/BAMS-D-11-00264.1. 
Keenan, T., and R. Carbone, 2008: Propagation and diurnal evolution of warm season cloudiness in the Australian and Maritime Continent region. Mon. Wea. Rev., 136, 973-994, https:// doi.org/10.1175/2007MWR2152.1.

Kumjian, M., J. Evans, and J. Guyer, 2006: The relationship of the Great Plains low level jet to nocturnal MCS development. 23rd Conf. on Severe Local Storms, St. Louis, MO, Amer. Meteor. Soc., P1.11, https://ams.confex.com/ams/23SLS/ techprogram/paper_115338.htm.

Lakshmanan, V., T. Smith, G. Stumpf, and K. Hondl, 2007: The warning decision support system-integrated information. Wea. Forecasting, 22, 596-612, https://doi.org/ 10.1175/WAF1009.1.

Li, Y., and R. B. Smith, 2010: The detection and significance of diurnal pressure and potential vorticity anomalies east of the Rockies. J. Atmos. Sci., 67, 2734-2751, https://doi.org/10.1175/ 2010JAS3423.1.

Lin, Y., R. D. Farley, and H. D. Orville, 1983: Bulk parameterization of the snow field in a cloud model. J. Climate Appl. Meteor., 22, 1065-1092, https://doi.org/10.1175/1520-0450 (1983) $022<1065$ :BPOTSF $>2.0 . \mathrm{CO} ; 2$.

Maddox, R. A., C. F. Chappell, and L. R. Hoxit, 1979: Synoptic and meso- $\alpha$ scale aspects of flash flood events. Bull. Amer. Meteor. Soc., 60, 115-123, https://doi.org/10.1175/1520-047760.2.115.

Mahajan, R., J. Derber, and D. T. Kleist, 2017: Proposed improvements to the NCEP GFS hybrid 4DEnVar configuration. 21st Conf. on Integrated Observing and Assimilation Systems for the Atmosphere, Oceans, and Land Surface, Seattle, WA, Amer. Meteor. Soc., 9.2, https://ams.confex. com/ams/97Annual/webprogram/Paper314311.html.

Marsham, J. H., S. B. Trier, T. M. Weckwerth, and J. W. Wilson, 2011: Observations of elevated convection initiation leading to a surface-based squall line during 13 June IHOP_2002. Mon. Wea. Rev., 139, 247-271, https://doi.org/10.1175/ 2010MWR3422.1.

Martin, W. J., and M. Xue, 2006: Sensitivity analysis of convection of the 24 May 2002 IHOP case using very large ensembles. Mon. Wea. Rev., 134, 192-207, https://doi.org/10.1175/ MWR3061.1.

Moncrieff, M. W., and C. Liu, 1999: Convection initiation by density currents: Role of convergence, shear, and dynamical organization. Mon. Wea. Rev., 127, 2455-2464, https://doi.org/ 10.1175/1520-0493(1999)127<2455:CIBDCR >2.0.CO;2.

Nakanishi, M., and H. Niino, 2006: An improved Mellor-Yamada level-3 model: Its numerical stability and application to a regional prediction of advection fog. Bound.-Layer Meteor., 119, 397-407, https://doi.org/10.1007/s10546-005-9030-8.

Nasrollahi, N., A. AghaKouchak, J. Li, X. Gao, K. Hsu, and S. Sorooshian, 2012: Assessing the impacts of different WRF precipitation physics in hurricane simulations. Wea. Forecasting, 27, 1003-1016, https://doi.org/10.1175/WAF-D-1005000.1 .

NOAA, 2004: Summary of natural hazard statistics for 2004 in the United States. NOAA/NWS, accessed 1 July 2016, http://www. nws.noaa.gov/om/hazstats/sum04.pdf.

— 2013: NWS text product archive. NOAA/NWS, accessed 1 July 2016, https://mesonet.agron.iastate.edu/wx/afos/ list.phtml.

Pan, Y., K. Zhu, M. Xue, X. Wang, M. Hu, S. G. Benjamin, S. S. Weygandt, and J. S. Whitaker, 2014: A GSI-based coupled EnSRF-En3DVar hybrid data assimilation system for the operational Rapid Refresh Model: Tests at a reduced resolution. Mon. Wea. Rev., 142, 3756-3780, https://doi.org/ 10.1175/MWR-D-13-00242.1.

Parker, M. D., and D. A. Ahijevych, 2007: Convective episodes in the east-central United States. Mon. Wea. Rev., 135, 37073727, https://doi.org/10.1175/2007MWR2098.1.

Pitchford, K. L., and J. London, 1962: The low-level jet as related to nocturnal thunderstorms over Midwest United States. J. Appl. Meteor., 1, 43-47, https://doi.org/10.1175/ 1520-0450(1962)001<0043:TLLJAR > 2.0.CO;2.

Reif, D. W., and H. B. Bluestein, 2017: A 20-year climatology of nocturnal convection initiation over the central and southern Great Plains during the warm season. Mon. Wea. Rev., 145, 1615-1639, https://doi.org/10.1175/MWR-D-16-0340.1.

Rochette, S. M., and J. T. Moore, 1996: Initiation of an elevated mesoscale convective system associated with heavy rainfall. Wea. Forecasting, 11, 443-457, https://doi.org/10.1175/15200434(1996)011<0443:IOAEMC>2.0.CO;2.

Rogers, E., and Coauthors, 2009: NCEP North American Mesoscale Modeling System: Recent changes and future plans. 19th Conf. on Numerical Weather Prediction/23rd Conf. on Weather Analysis and Forecasting, Omaha, NE, Amer. Meteor. Soc., 2A.4, https://ams.confex.com/ams/23WAF19NWP/ techprogram/paper_154114.htm.

Rutledge, G. K., J. Alpert, and W. Ebisuzaki, 2006: NOMADS: A climate and weather model archive at the National Oceanic and Atmospheric Administration. Bull. Amer. Meteor. Soc., 87, 327-342, https://doi.org/10.1175/BAMS-87-3-327.

Schwartz, C. S., and R. A. Sobash, 2017: Generating probabilistic forecasts from convection-allowing ensembles using neighborhood approaches: A review and recommendations. Mon. Wea. Rev., 145, 3397-3418, https://doi.org/10.1175/MWR-D16-0400.1.

Scorer, R., 1949: Theory of waves in the lee of mountains. Quart. J. Roy. Meteor. Soc., 75, 41-56, https://doi.org/10.1002/ qj. 49707532308 .

Skamarock, W. C., and Coauthors, 2008: A description of the Advanced Research WRF version 3. NCAR Tech. Note NCAR/TN-475+STR, 113 pp, https://doi.org/10.5065/ D68S4MVH.

Sobash, R. A., and D. J. Stensrud, 2015: Assimilating surface mesonet observations with the EnKF to improve ensemble forecasts of convection initiation on 29 May 2012. Mon. Wea. Rev., 143, 3700-3725, https://doi.org/10.1175/MWR-D-14-00126.1.

Stensrud, D. J., and R. A. Maddox, 1988: Opposing mesoscale circulations: A case study. Wea. Forecasting, 3, 189-204, https://doi.org/10.1175/1520-0434(1988)003<0189:OMCACS > 2.0. $\mathrm{CO} ; 2$.

Surcel, M., M. Berenguer, and I. Zawadzki, 2010: The diurnal cycle of precipitation from continental radar mosaics and numerical weather prediction models. Part I: Methodology and seasonal comparison. Mon. Wea. Rev., 138, 3084-3106, https://doi.org/ 10.1175/2010MWR3125.1.

Tao, W.-K., and Coauthors, 2003: Microphysics, radiation and surface processes in the Goddard Cumulus Ensemble (GCE) model. Meteor. Atmos. Phys., 82, 97-137, https://doi.org/ 10.1007/s00703-001-0594-7.

Thompson, T., 2014: Ensemble Kalman filter methods for convective-scale radar data assimilation and multi-scale data assimilation of the 13 June 2010 tornadic supercell environment. Ph.D. dissertation, School of Meteorology, University of Oklahoma, 233 pp.

Tong, M., and M. Xue, 2005: Ensemble Kalman filter assimilation of Doppler radar data with a compressible nonhydrostatic 
model: OSS experiments. Mon. Wea. Rev., 133, 1789-1807, https://doi.org/10.1175/MWR2898.1.

Torn, R. D., G. J. Hakim, and C. Snyder, 2006: Boundary conditions for limited-area ensemble Kalman filters. Mon. Wea. Rev., 134, 2490-2502, https://doi.org/10.1175/MWR3187.1.

Trier, S. B., and D. B. Parsons, 1993: Evolution of environmental conditions preceding the development of a nocturnal mesoscale convective complex. Mon. Wea. Rev., 121, 1078-1098, https:// doi.org/10.1175/1520-0493(1993)121<1078:EOECPT>2.0.CO;2.

Wallace, J. M., 1975: Diurnal variations in precipitation and thunderstorm frequency over the conterminous United States. Mon. Wea. Rev., 103, 406-419, https://doi.org/10.1175/15200493(1975)103<0406:DVIPAT>2.0.CO;2.

Wang, X., and T. Lei, 2014: GSI-based four-dimensional ensemble-variational (4DEnsVar) data assimilation: Formulation and single-resolution experiments with real data for NCEP Global Forecast System. Mon. Wea. Rev., 142, 33033325, https://doi.org/10.1175/MWR-D-13-00303.1.

— D. M. Barker, C. Snyder, and T. M. Hamill, 2008: A hybrid ETKF-3DVAR data assimilation scheme for the WRF Model. Part II: Real observation experiments. Mon. Wea. Rev., 136, 5132-5147, https://doi.org/10.1175/2008MWR2445.1.

—, D. Parrish, D. Kleist, and J. Whitaker, 2013: GSI 3DVarbased ensemble-variational hybrid data assimilation for NCEP Global Forecast System: Single-resolution experiments. Mon. Wea. Rev., 141, 4098-4117, https://doi.org/ 10.1175/MWR-D-12-00141.1.

Wang, Y., and X. Wang, 2017: Direct assimilation of radar reflectivity without tangent linear and adjoint of the nonlinear observation operator in the GSI-based EnVar system: Methodology and experiment with the 8 May 2003 Oklahoma City tornadic supercell. Mon. Wea. Rev., 145, 1447-1471, https:// doi.org/10.1175/MWR-D-16-0231.1.

Weckwerth, T. M., and D. B. Parsons, 2006: A review of convection initiation and motivation for IHOP_2002. Mon. Wea. Rev., 134, 5-22, https://doi.org/10.1175/MWR3067.1.
Whitaker, J. S., and T. M. Hamill, 2002: Ensemble data assimilation without perturbed observations. Mon. Wea. Rev., 130, 1913-1924, https://doi.org/10.1175/1520-0493(2002)130<1913: EDAWPO $>2.0 . \mathrm{CO} ; 2$.

— , and —, 2012: Evaluating methods to account for system errors in ensemble data assimilation. Mon. Wea. Rev., 140, 3078-3089, https://doi.org/10.1175/MWR-D-11-00276.1.

Wilson, J. W., and W. E. Schreiber, 1986: Initiation of convective storms at radar-observed boundary-layer convergence lines. Mon. Wea. Rev., 114, 2516-2536, https://doi.org/10.1175/ 1520-0493(1986) $114<2516:$ IOCSAR $>2.0$.CO;2.

— , and R. D. Roberts, 2006: Summary of convective storm initiation and evolution during IHOP: Observational and modeling perspective. Mon. Wea. Rev., 134, 23-47, https://doi.org/ 10.1175/MWR3069.1.

Xue, M., and W. J. Martin, 2006: A high-resolution modeling study of the 24 May 2002 dryline case during IHOP. Part I: Numerical simulation and general evolution of the dryline and convection. Mon. Wea. Rev., 134, 149-171, https://doi.org/ 10.1175/MWR3071.1.

Yussouf, N., and D. J. Stensrud, 2010: Impact of phased-array radar observations over a short assimilation period: Observing system simulation experiments using an ensemble Kalman filter. Mon. Wea. Rev., 138, 517-538, https://doi.org/10.1175/ 2009MWR2925.1.

— D. C. Dowell, L. J. Wicker, K. H. Knopfmeier, and D. M. Wheatley, 2015: Storm-scale data assimilation and ensemble forecasts for the 27 April 2011 severe weather outbreak in Alabama. Mon. Wea. Rev., 143, 3044-3066, https://doi.org/ 10.1175/MWR-D-14-00268.1.

Zhu, K., Y. Pan, M. Xue, X. Wang, J. S. Whitaker, S. G. Benjamin, S. S. Weygandt, and M. Hu, 2013: A regional GSI-based ensemble Kalman filter data assimilation system for the rapid refresh configuration: Testing at reduced resolution. Mon. Wea. Rev., 141, 4118-4139, https://doi.org/10.1175/MWR-D13-00039.1. 